\title{
Mechanical Response of Castlegate Sandstone under Hydrostatic Cyclic Loading
}

\author{
William M. Kibikas $\mathbb{D}^{1,2}$ and Stephen J. Bauer $\mathbb{D}^{2}$ \\ ${ }^{1}$ School of Geosciences, University of Oklahoma, 100 E. Boyd St., Norman, OK 73019, USA \\ ${ }^{2}$ Sandia National Laboratories, Geothermal Department, MS 1033 PO Box 5800, Albuquerque, NM 87185, USA \\ Correspondence should be addressed to William M. Kibikas; wmkibikas@ou.edu
}

Received 22 September 2020; Revised 2 April 2021; Accepted 7 April 2021; Published 24 April 2021

Academic Editor: orlando vaselli

Copyright ( 2021 William M. Kibikas and Stephen J. Bauer. This is an open access article distributed under the Creative Commons Attribution License, which permits unrestricted use, distribution, and reproduction in any medium, provided the original work is properly cited.

\begin{abstract}
The stress history of rocks in the subsurface affects their mechanical and petrophysical properties. Rocks can often experience repeated cycles of loading and unloading due to fluid pressure fluctuations, which will lead to different mechanical behavior from static conditions. This is of importance for several geophysical and industrial applications, for example, wastewater injection and reservoir storage wells, which generate repeated stress perturbations. Laboratory experiments were conducted with Castlegate sandstone to observe the effects of different cyclic pressure loading conditions on a common reservoir analogue. Each sample was hydrostatically loaded in a triaxial cell to a low effective confining pressure, and either pore pressure or confining pressure was cycled at different rates over the course of a few weeks. Fluid permeability was measured during initial loading and periodically between stress cycles. Samples that undergo cyclic loading experience significantly more inelastic (nonrecoverable) strain compared to samples tested without cyclic hydrostatic loading. Permeability decreases rapidly for all tests during the first few days of testing, but the decrease and variability of permeability after this depend upon the loading conditions of each test. Cycling conditions do affect the mechanical behavior; the elastic moduli decrease with the increasing loading rate and stress cycling. The degree of volumetric strain induced by stress cycles is the major control on permeability change in the sandstones, with less compaction leading to more variation from measurement to measurement. The data indicate that cyclic loading degrades permeability and porosity more than static conditions over a similar period, but the petrophysical properties are dictated more by the hydrostatic loading rate rather than the total length of time stress cycling is imposed.
\end{abstract}

\section{Introduction}

Over long time scales, the state of stress in the subsurface is generally static with strain rates around $10^{-15} \mathrm{~s}^{-1}$. However, repeated fluctuations in stress are also quite common over long periods of time; recurring migration of hydrothermal fluids and seismic activity may regularly alter the stress state throughout the subsurface $[1,2]$. On shorter time scales, stress changes are often induced in the near-wellbore environment of natural gas storage reservoirs, wastewater injection, and geothermal projects, where pressurizations during injection, followed by shut-ins and depressurization, are ever-present [3-7]. Such stress changes are expected to alter the mechanical behavior of rocks in situ compared to the predicted response for a static stress state $[8,9]$.

Rock behavior is often dependent on the "path" taken to reach the current stress state. This dependency is often referred to as stress history [10] and is a function of both the pressure dependency and time dependency of rock behavior. The stress history has been shown to affect a number of mechanical properties in rocks, including their elastic moduli [11, 12], elastic wave velocity $[13,14]$, and permeability [15]. The impact of stress history on rock behavior is most clearly demonstrated in rocks that have been subjected to repeated cyclic loading $[10,12,16]$. As stress is cycled, whether under hydrostatic $\left(\sigma_{1}\right.$ $\left.=\sigma_{2}=\sigma_{3}\right)$ or shear loading conditions $\left(\sigma_{1} \neq \sigma_{2} \neq \sigma_{3}\right)$, rock 
properties have been shown to evolve in a nonlinear manner despite the state of stress remaining relatively unchanged.

Cyclic loading is particularly relevant to analyzing the long-term behavior of rocks in the subsurface subject to repeated stress changes. These stress perturbations likely lead to an evolution of rock behavior that depends heavily on the specifics of the lithology and loading paths taken. For many injection and recovery projects, where stress changes are pervasive and frequent, cyclic loading can significantly affect the prospective reservoir and its stability near the wellbore. Critical reservoir properties such as permeability are dependent upon the current stress state and stress history induced [17]. Furthermore, pervasive stress changes can lead to irreversible deformation that may degrade or even compromise near-wellbore rock conditions. For example, repeated pore pressure cycling can induce reservoir compaction and subsidence [18] and can either mitigate or enhance mild-tomoderate seismic activity [19]. The risk involved presents a critical need to understand the impacts of different stress histories in such reservoirs.

Sandstones are a prominent reservoir rock type. Extensive research has been conducted to understand their hydromechanical behavior under hydrostatic and shear loading conditions (Zoback and Byerlee; [12, 20-22]). However, much of this research has focused on the interrelation of sandstone porosity and permeability with pressure. Less work has been focused on how stress cycling affects the porosity and permeability of sandstones, especially when the mean effective stress is near-constant. Dey [23] measured the permeability and electrical resistivity changes with the cycling of hydrostatic effective stress for two sandstones. Sandstone permeability was shown to evolve with stress cycling depending on the effective stress, fluid composition, and clay content of different sandstones. Bernabe [10] found that the petrophysical properties of sandstone during hydrostatic cycling depended on the time for consolidation between cycles, whether confining or pore pressure was cycled, hysteresis, and the number of cycles conducted. Keaney et al. [24] found that the permeability of sandstone was dependent upon both the effective stress and the stress history. Heap et al. [25] showed that cycling sandstone pore pressure, while maintaining constant effective pressure, during creep experiments did not affect deformation rates. Little attention has been given to how sandstone properties evolve with stress cycling at low effective pressures or how properties relate to the loading rate, stress cycle amplitude and period, and total compaction.

In this work, the effects of cyclic loading were measured on a reservoir analogue sandstone to observe the evolution of rock mechanical and petrophysical properties. Hydrostatic loading tests were conducted with varying loading conditions, utilizing different cycling rates, effective stresses, and test durations. Change in permeability was monitored at variable intervals evaluating the impact of stress history on sandstone transport properties.

\section{Materials and Methodology}

2.1. Materials. The samples tested in this study were Castlegate sandstone. The authors have previously worked with this material and have established its efficacy as a good reservoir analogue [11]. As a fluvial reservoir rock from the Mesaverde Group in Utah, Castlegate sandstone is composed predominantly of quartz $(\sim 90 \%)$ and calcite cement, with accessory minerals including feldspars and Fe-rich clays $[11,26]$. Grain size on average varies from $0.2 \mathrm{~mm}$ to $2.5 \mathrm{~mm}$, with an average porosity of $\sim 26 \pm 0.3$ and low preexisting fracture content (Figure 1). Samples were cored perpendicular to bedding and ground into right cylinders with dimensions of $\sim 8.2 \mathrm{~cm}$ by $3.8 \mathrm{~cm}$ (Table 1). Samples were oven-dried for 48 hours at $60^{\circ} \mathrm{C}$ and then weighed to find their dry weight and density (Table 1).

2.2. Stress Cycling Tests. The test specimen was placed between two metal platens having central ports that permit the permeant (water) to enter and exit (Figure 2(a)). Highly permeable, porous felt metal disks were placed in the interface between the platens and specimen to distribute the permeant and permeant pressure across the full cross section of the specimen. The specimen is jacketed with a paint-on, UVcured polyurethane-sealed by adhesion to the platens and rock-and serves to protect the specimen from hydraulic confining fluid and to prevent permeant from short circuiting around the sides of the specimen during testing. Sample displacement was measured by attaching linear voltage displacement transducers (LVDTs) to the sample setup. Axial displacement (i.e., perpendicular to bedding) was measured with an LVDT attached to the end caps of the sample, while lateral displacement (i.e., parallel to bedding) was measured by using a pair of LVDTs attached to the center of the sample.

The sample assembly is placed into the pressure vessel (Figure 2(b)). The pressure vessel was then filled with confining fluid (Isopar $\mathrm{H}$ fluid). A low confining pressure $(\sim 0.5 \mathrm{MPa})$ was maintained as tap water was injected into the sample and pressure vessel to degas the system. Water was pressurized into the sample through a pair of syringe pumps until the system achieved effective saturation. The water pressure line was burped a few times to release trapped air. A low water flow rate was maintained to prevent sample pore pressure from exceeding applied confining pressure.

Once the sample and pore system were effectively saturated, tests could begin. A general schematic of the test procedure can be seen in Figure 3. The specific conditions for each test are listed in Table 2. Confining pressure $\left(P_{c}\right)$ was generally increased first to a static value, either at a constant rate or in increments of $0.69 \mathrm{MPa}$. Once confining pressure value was achieved, pore pressure was increased to the maximum pore pressure used in each test experiment (Table 2). After the effective pressure was stabilized, hydrostatic pressure cycling was initiated. Either confining pressure or pore pressure was then decreased at a constant rate until the minimum effective pressure was achieved, whereby the stress was increased at the same rate back to the maximum effective pressure. Hydrostatic stress was cycled in this manner continuously until the test ended, wherein stress was unloaded at a constant rate. Cycling was periodically halted to lower confining and pore pressure and measure current permeability across the sample. The only exception to this was CG_009, which 


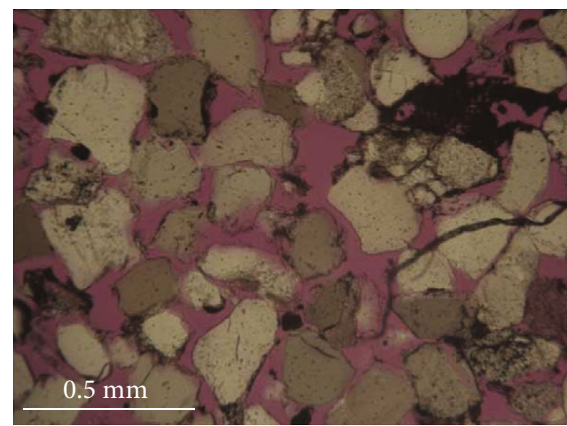

FIGURE 1: Photomicrograph of undeformed Castlegate sandstone.

TABLE 1: Dimensions of Castlegate sandstone samples tested in this study.

\begin{tabular}{lcccc}
\hline $\begin{array}{l}\text { Sample } \\
\text { number }\end{array}$ & $\begin{array}{c}\text { Length } \\
(\mathrm{cm})\end{array}$ & $\begin{array}{c}\text { Diameter } \\
(\mathrm{cm})\end{array}$ & $\begin{array}{c}\text { Weight } \\
(\mathrm{g})\end{array}$ & $\begin{array}{c}\text { Density } \\
\left(\mathrm{g} / \mathrm{cm}^{3}\right)\end{array}$ \\
\hline CG_001 & 8.18 & 3.77 & 178.58 & 1.96 \\
CG_003 & 8.15 & 3.78 & 178.31 & 1.95 \\
CG_004 & 8.15 & 3.78 & 178.84 & 1.95 \\
CG_005 & 8.22 & 3.77 & 179.17 & 1.96 \\
CG_006 & 8.19 & 3.74 & 175.40 & 1.95 \\
CG_007 & 8.24 & 3.74 & 178.08 & 1.96 \\
CG_009 & 8.21 & 3.75 & 177.40 & 1.95 \\
CG_010 & 8.23 & 3.76 & 178.90 & 1.96 \\
\hline
\end{tabular}

was kept at a constant effective stress of $10.34 \mathrm{MPa}$ except during permeability tests. Although the average effective stress during the cycling tests was 1.5-2 MPa greater than the average effective stress in CG_009, the difference in pressure is small and thus the test conditions are still comparable. All measurements were recorded with a sampling rate of $8.33 \times 10^{-3} \mathrm{~Hz}$.

This work adopts the geomechanical convention of compression stresses and strains as positive. Effective pressure was calculated through the difference of the confining pressure $\left(P_{c}\right)$ and pore pressure $\left(P_{p}\right)$. Axial displacement and lateral displacement measured were used to calculate the axial $\left(\varepsilon_{\mathrm{ax}}\right)$ and radial $\left(\varepsilon_{\mathrm{rad}}\right)$ strains, respectively. Volumetric strain $\left(\varepsilon_{\mathrm{v}}\right)$ was calculated using the following formula:

$$
\varepsilon_{\mathrm{v}}=\varepsilon_{\mathrm{ax}}+2 \varepsilon_{\mathrm{rad}} .
$$

All strains measured are reported as percent strain. The displacements are accurate within $0.0127 \mathrm{~mm}$, while the confining pressure and pore pressures are accurate within $0.0344 \mathrm{MPa}$.

2.3. Permeability Measurements. To measure permeability, a pressure difference was generated by dropping pore pressure at one end of the sample while maintaining it at the other end. The difference in the pore pressure across the sample was then used to calculate permeability using Darcy's law:

$$
k=\frac{Q L \mu}{A \Delta p}
$$

where $k$ is the sample permeability, $Q$ is the volumetric flow rate, $\mu$ is the dynamic viscosity, $L$ and $A$ are the sample length and area, respectively, and $\Delta p$ is the pore pressure drop between the sample ends. The fluid flow rate was kept constant for each test $\left(\sim 8 \times 10^{-8} \mathrm{~m}^{3} / \mathrm{s}\right)$. The sample length and area were adjusted based on the displacement measured by axial and radial LVDTs.

All permeabilities were measured during testing at low pore pressure values $(\sim 0.1-0.2 \mathrm{MPa})$. The use of a low pore pressure was due to a limitation of the testing setup. Permeability was determined at different intervals and conditions depending on the hydrostatic loading conditions. Permeabilities of CG_001 and CG_003 samples were determined prior to and after hydrostatic loading, at low confining pressures. For the other six tests, permeabilities were determined by reducing the confining pressure and pore pressure to lower values concomitantly to minimize change in effective stress. Once pore pressure was at the desired value, permeability was measured. At each halt in stress cycling, permeability was recorded twice. Confining pressure during each measurement was maintained at an effective pressure equivalent to either the maximum or minimum value during cycling (see Table 2).

\section{Experimental Results}

3.1. Deformation Data. The axial and radial strains of each specimen for the duration of each test are shown in Figure 4, while volumetric strains with cycling of effective pressure are shown in Figure 5. The strains are shown against both time and effective pressure to illustrate the combined impact mechanical load, dynamic stress state, and time elapsed have on the specimen. Strong anisotropy is observed between the strains despite hydrostatic pressure conditions being applied. Axial deformation is universally 2-6 times greater than radial deformation, regardless of effective stress during cycling, cycling rate, or test duration (Figure 4). Moreover, axial strain is more sensitive to fluctuations in stress induced by hydrostatic pressure cycling. This anisotropy of deformation is likely an inherent characteristic of the specific lithology, given its ubiquity between samples, with the degree of anisotropy being attributable to sampleto-sample variations. Such deformation anisotropy is likely a function of the bedding orientation. The axial and radial strains are parallel and perpendicular to sandstone bedding planes, respectively, so the greater axial deformation is likely indicative of the greater closure of preexisting microcracks subparallel to the bedding planes [27].

Volumetric strain curves shown in Figure 5 demonstrate that the range and mean of effective pressures were nearly constant during loading, except during permeability tests. Although minor variations exist in the conditions (see Table 2), the minimum and maximum effective pressures during cycling vary by at most $1-2 \mathrm{MPa}$ during testing. 


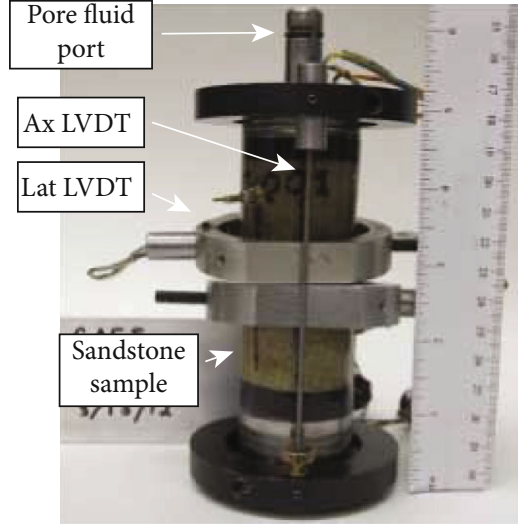

(a)

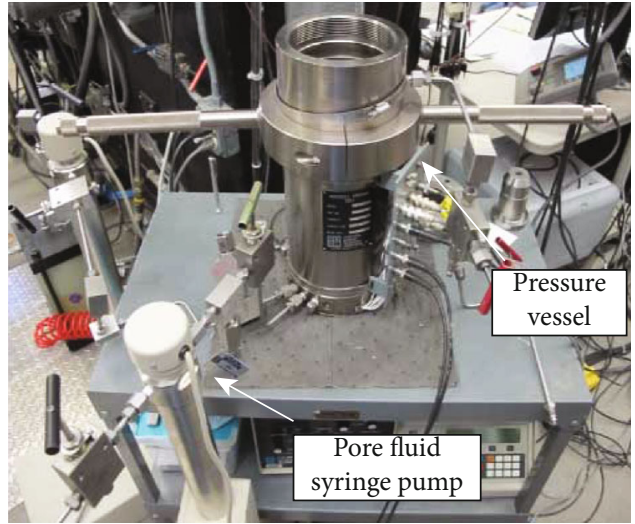

(b)

FIGURE 2: Setup for hydrostatic tests: (a) sample configuration for samples during hydrostatic tests; (b) pressure vessel and pumps utilized for conducting each experiment.

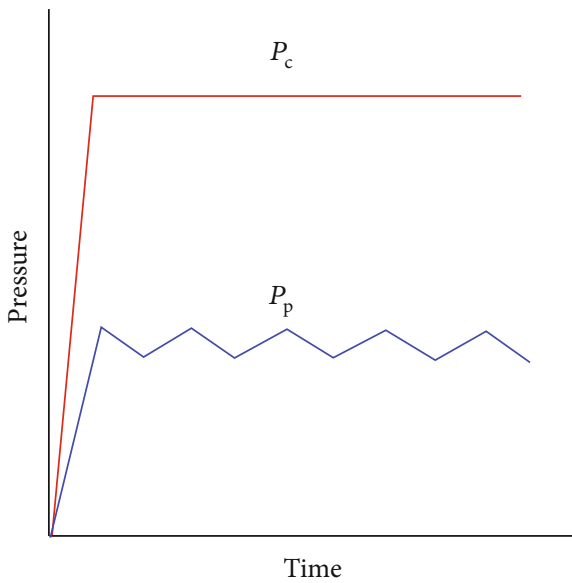

(a)

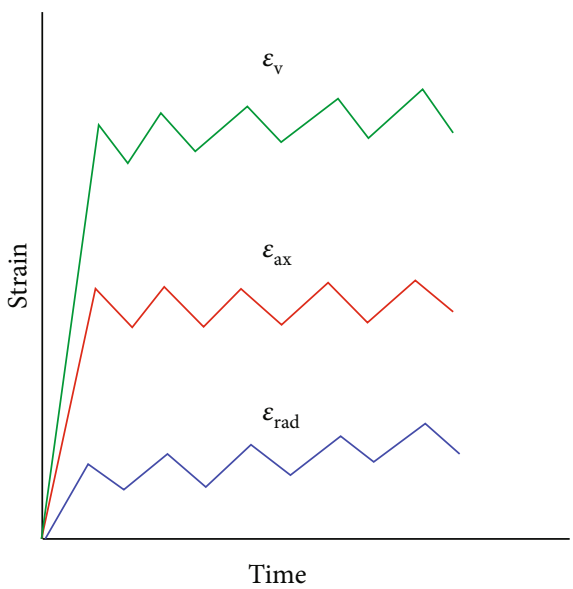

(b)

FIgURE 3: Model of stress-strain evolution over time during cyclic loading tests: (a) plot of confining pressure $\left(P_{\mathrm{c}}\right)$ and pore pressure $\left(P_{\mathrm{p}}\right)$ over test duration; (b) plot of axial $\left(\varepsilon_{\mathrm{ax}}\right)$, radial $\left(\varepsilon_{\mathrm{rad}}\right)$, and volumetric $\left(\varepsilon_{\mathrm{v}}\right)$ strains over test duration.

TABLE 2: Testing conditions for each hydrostatic loading test. Tests with multiple pressure conditions indicate maximum and minimum pressure of each cycle. $P_{\mathrm{c}}=$ confining pressure; $P_{\mathrm{p}}=$ pore pressure; $P_{\text {eff }}=$ effective pressure during cycles; $P_{\mathrm{k}}=$ effective pressure during permeability tests. When two values of $P_{\mathrm{c}}, P_{\mathrm{p}}, P_{\text {eff }}$, or $P_{\mathrm{k}}$ are listed, this represents the maximum and minimum pressure of each cycle.

\begin{tabular}{|c|c|c|c|c|c|c|c|}
\hline Sample number & $P_{c}(\mathrm{MPa})$ & $P_{\mathrm{p}}(\mathrm{MPa})$ & $P_{\text {eff }}(\mathrm{MPa})$ & $P_{\mathrm{k}}(\mathrm{MPa})$ & Cycle time (hours) & \# of cycles & Duration (days) \\
\hline CG_001 & 20.68 & $10.34 \& 6.89$ & $10.34 \& 13.79$ & 0.55 & 8 & 5 & 2 \\
\hline CG_003 & 20.68 & $10.34 \& 6.89$ & $10.34 \& 13.79$ & 0.55 & 8 & 28 & 10 \\
\hline CG_004 & 20.68 & $10.34 \& 6.89$ & $10.34 \& 13.79$ & $10.17 \& 6.72$ & 8 & 44 & 16 \\
\hline CG_005 & 20.68 & $11.03 \& 6.20$ & $9.65 \& 14.48$ & $10.89 \& 6.07$ & 8 & 60 & 23 \\
\hline CG_006 & 20.68 & $11.03 \& 6.20$ & $9.65 \& 14.48$ & $10.76 \& 5.93$ & 4 & 168 & 32 \\
\hline CG_007 & $14.82 \& 10$ & 0.35 & $9.65 \& 14.47$ & $14.48 \& 9.65$ & 4 & 117 & 22 \\
\hline CG_009 & 20.68 & 10.34 & 10.34 & 10.27 & - & - & 31 \\
\hline CG_010 & 20.68 & $10.34 \& 6.20$ & $10.34 \& 14.48$ & 10.34 & 2 & 274 & 33 \\
\hline
\end{tabular}

Therefore, the differences seen between the individual stressstrain curves can be attributed to factors other than the mean stress applied during each test, such as the cycle frequency or loading rate.
Typical of sandstones, during the initial hydrostatic loading portion of each test, the stress-strain curve is initially concave up as nonrecoverable or inelastic damage is accumulated in the sample via grain rearrangement, elastic 

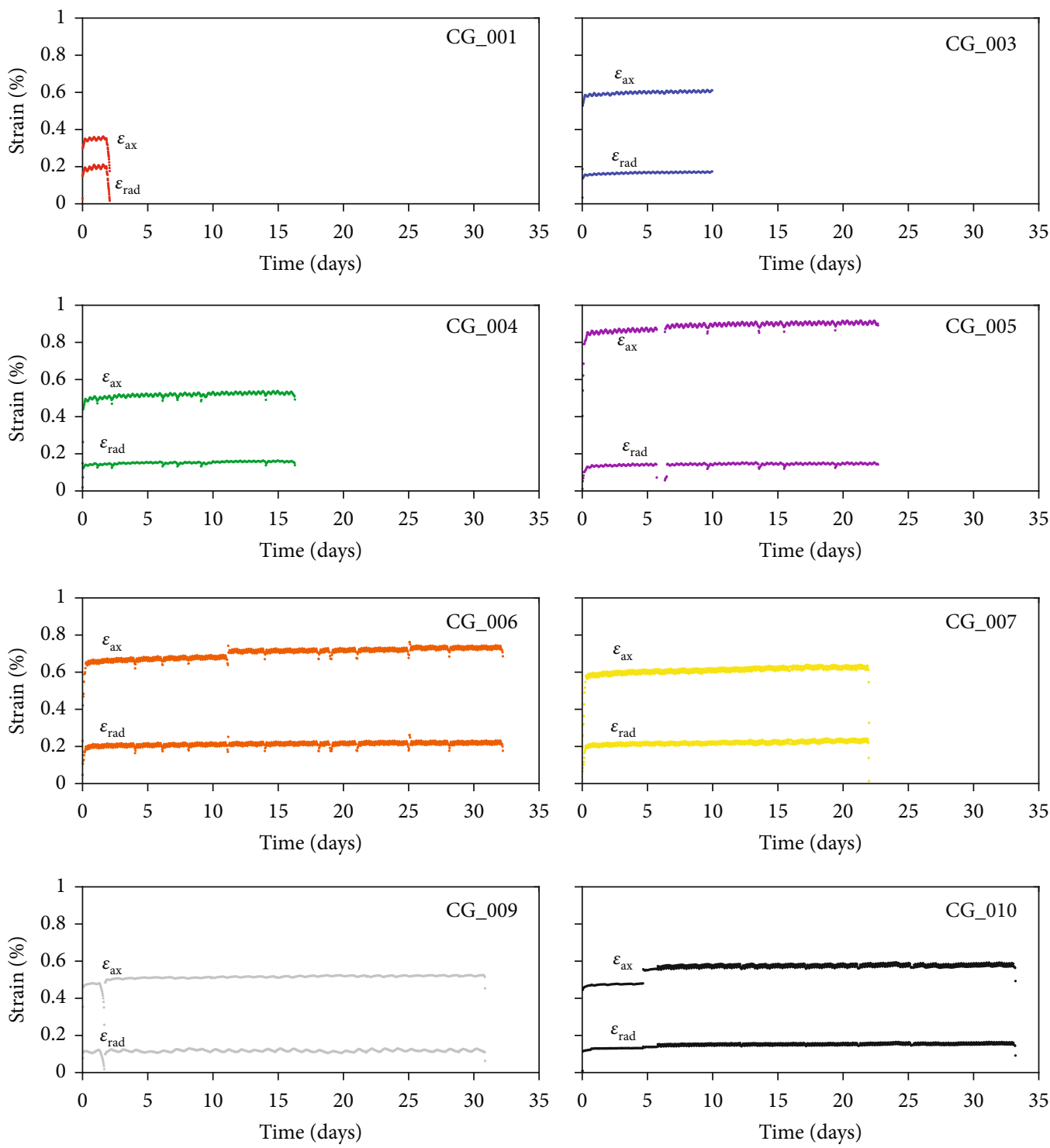

Figure 4: Axial and radial strains for duration of each test.

crack closure, and fracturing of cement at grain contacts (e.g., [21]). The volumetric stress-strain relationship becomes approximately linear-elastic after 5-10 MPa. As cycling of hydrostatic stress occurs, volumetric strain can be seen to accumulate over time. Of note is that CG_009, which was kept a constant effective pressure for 32 days, shows very little accumulated strain throughout the experiment. Furthermore, when each other cycled stress test was ended and the pressure released, the total inelastic volumetric strain for the cycled stress tests varied from 0.2 to $0.8 \%$, while the permanent strain in CG_009 was less than 0.1\% (Table 3).

Figure 6 shows how the change in volumetric strain evolves as hydrostatic stress cycling continues. Volumetric strain change is calculated from the difference in the peak and valley of each cycle during the unloading portion. During the first few cycles and days of stress cycling, the change in strain during cycle unloading increases with each successive cycle, after which the strain changes during cycle unloading become more consistent for the duration of the tests. Volu- metric strain per cycle increases as the difference between the maximum and minimum stress increases. CG_006 and CG_007 have the largest stress difference during cycling and similarly display the greatest strain change among the tests, followed by CG_010 and then CG_005, CG_004, and CG_003. CG_005 does not seemingly follow this trend, as pressure change for this matches that of CG_006 and $\mathrm{CG}_{-}$ 007 but exhibits behavior more akin to CG_003 and $\mathrm{CG}_{-}$ 004. It is feasible that this is the influence of the pressurization rate instead, as all three are cycled in 8-hour intervals rather than 4-hour intervals like CG_006 and CG_007. Additionally, there appears to be different trends in the volumetric strain change depending on the loading conditions. Samples cycled at 8-hour rates exhibit greater strain change over time, while samples cycled at 4-hour rates exhibit little change in volumetric strain over time (CG_006) or even minute decreases after a certain time (CG_007). CG_010 on the other hand experiences a steady decrease in volumetric strain change over time (Figure 6(b)). Such behavior implies that 

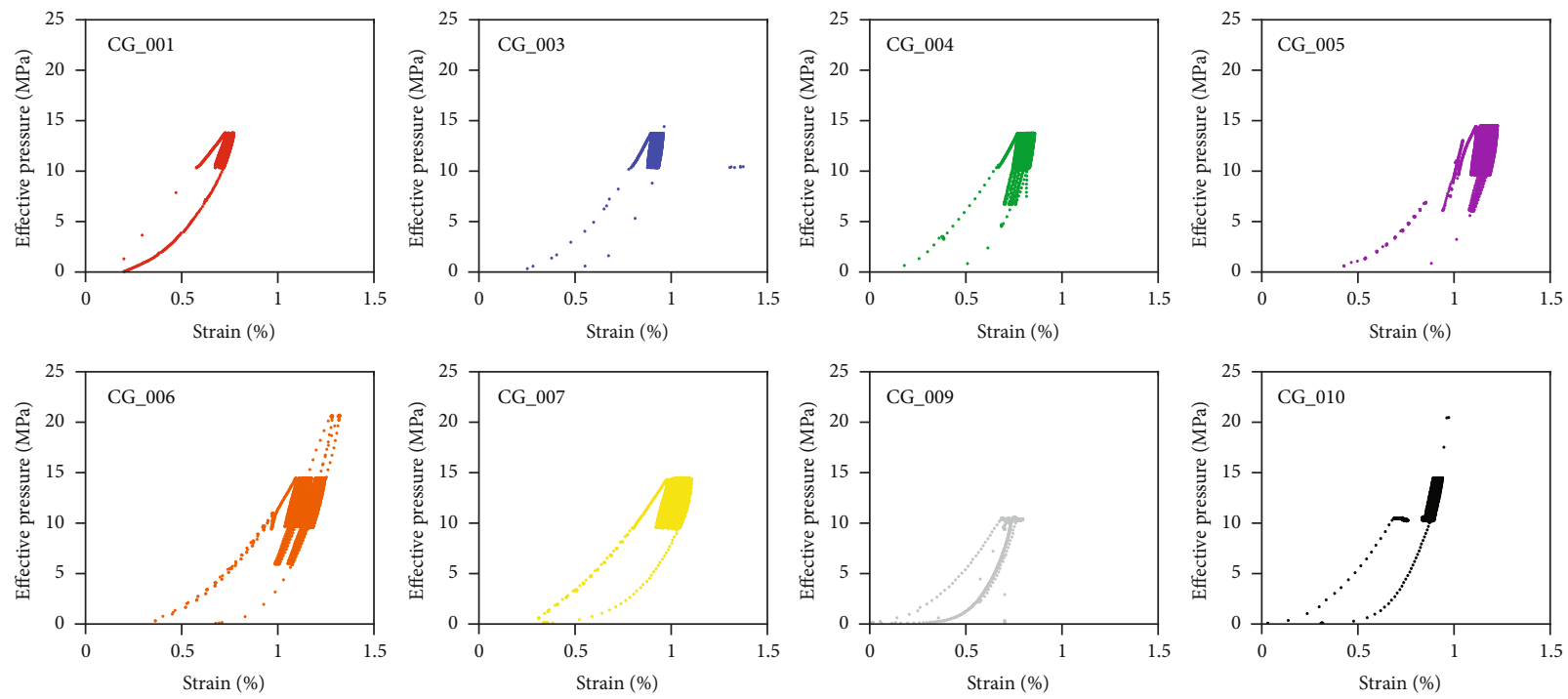

FIgURE 5: Volumetric strain as a function of effective stress.

TABLE 3: Values of the bulk modulus $B$ measured during hydrostatic loading at test inception and unloading at test ending. Unloading $\varepsilon_{\mathrm{v}}$ is the volumetric strain calculated from a third-degree polynomial best fit of the unloading curve. Test duration indicates the number of days each test lasted. Cycle loading rate represents the rate of effective stress change during cyclic loading.

\begin{tabular}{lcccc}
\hline $\begin{array}{l}\text { Sample } \\
\text { number }\end{array}$ & $\begin{array}{c}\text { Loading } B \\
(\mathrm{GPa})\end{array}$ & $\begin{array}{c}\text { Unloading } \\
B(\mathrm{GPa})\end{array}$ & $\begin{array}{c}\text { Cycle loading } \\
\text { rate }(\mathrm{MPa} / \mathrm{hr})\end{array}$ & $\begin{array}{c}\text { Unloading } \\
\varepsilon_{\mathrm{v}}(\%)\end{array}$ \\
\hline CG_001 & 2.38 & 3.18 & 0.86 & 0.179 \\
CG_003 & 2.88 & 4.50 & 0.86 & 0.540 \\
CG_004 & 2.61 & 5.24 & 0.86 & 0.449 \\
CG_005 & 2.14 & 5.03 & 1.21 & 0.752 \\
CG_006 & 2.27 & 4.40 & 2.42 & 0.652 \\
CG_007 & 2.21 & 3.40 & 2.41 & 0.282 \\
CG_009 & 2.64 & 5.52 & - & 0.025 \\
CG_010 & 2.27 & 4.94 & 4.14 & 0.266 \\
\hline
\end{tabular}

loading rate controls how the sandstone samples will respond to further stress cycling.

3.2. Permeability Data. The permeability values determined for each sample are shown in Figure 7 . Figure 7 (a) shows the permeabilities measured for the 8-hour tests, including those for CG_001 and CG_003 where permeability was measured at low confining pressures $(\sim 0.55 \mathrm{MPa})$ before and hydrostatic loading began. All samples experience a general decrease in permeability over time, though the rate seems to vary from sample to sample.

Figure 7(b) shows permeabilities determined for the 4hour, 2-hour, and no cycling tests. As with Figure 7(a), permeability is shown to decrease quickly at the start of each test and then decrease in a quasilinear manner over time. The change in flow rate with time in CG_009 can be seen to be less than that of the other tests, where stress cycling occurred. Likewise, the flow rate over time decreases less in CG_010 than in either CG_006 or CG_007, which were cycled at slower rates than CG_010. Such an observation implies that permeability is not inextricably linked to test duration alone. The relative similarity between the CG_006 and CG_007 is also noteworthy, as the former involves cycling of pore pressure while the latter involves cycling of confining pressure. Furthermore, the effective pressures $P_{\mathrm{k}}$ at which permeabilities were measured was nearly $4 \mathrm{MPa}$ greater in CG_007.

Figure $7(\mathrm{c})$ shows the permeability measured for $\mathrm{CG}_{-}$ 005, CG_006, and CG_007 where confining pressure was increased in a stepwise manner during the initial loading stage. The measurements shown suggest that the flow rate is not significantly altered by increasing confining pressure, at least for relatively low confining pressures (i.e., 0$12 \mathrm{MPa}$ ). Although CG_005 and CG_006 show a little trend in the measurements as confining pressure increases, measurements with CG_007 are fairly constant with little decrease or increase. One observation is that CG_005 displays variable, high permeability values initially (Figure $7(\mathrm{c})$ ). However, for pressures greater than $8 \mathrm{MPa}$, the flow rate decreases rapidly to $4-5 \times 10^{-13} \mathrm{~m}^{2}$ and becomes far less variable than at lower confining pressures. In Figure 5, the volumetric strain of CG_005 can be shown to increase sharply at this pressure as well; this is not observed in any of the other tests. This may indicate that permeability through the samples is more a function of the volumetric strain than the pressure applied.

\section{Analysis and Discussion}

4.1. Evolution of Sandstone Mechanical Behavior. Since the porosity is a first-order control on the mechanical behavior of sandstones, it follows that continued porosity reduction or volumetric strain will lead to concomitant changes in the elastic and inelastic deformation. In high-porosity sandstones $(>\sim 15 \%)$, reduction due to hydrostatic compaction occurs primarily through the mechanisms of grain rearrangement and grain sliding [28]. During hydrostatic compaction, stress and strain have a quasilinear relationship before the 


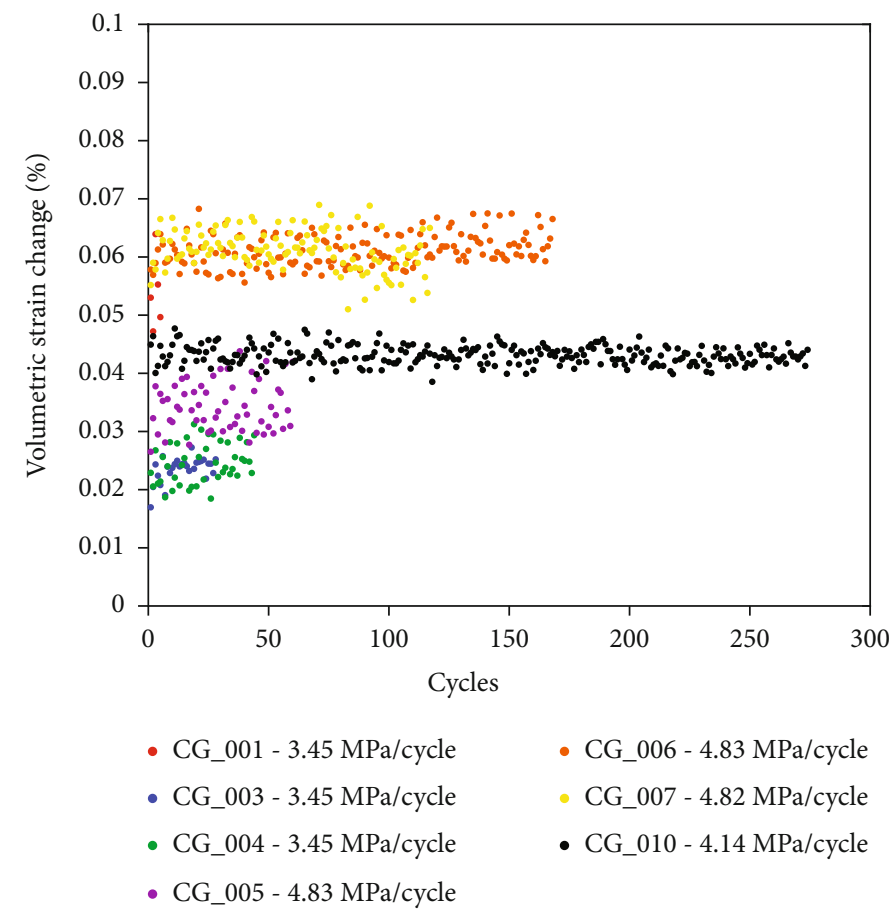

(a)

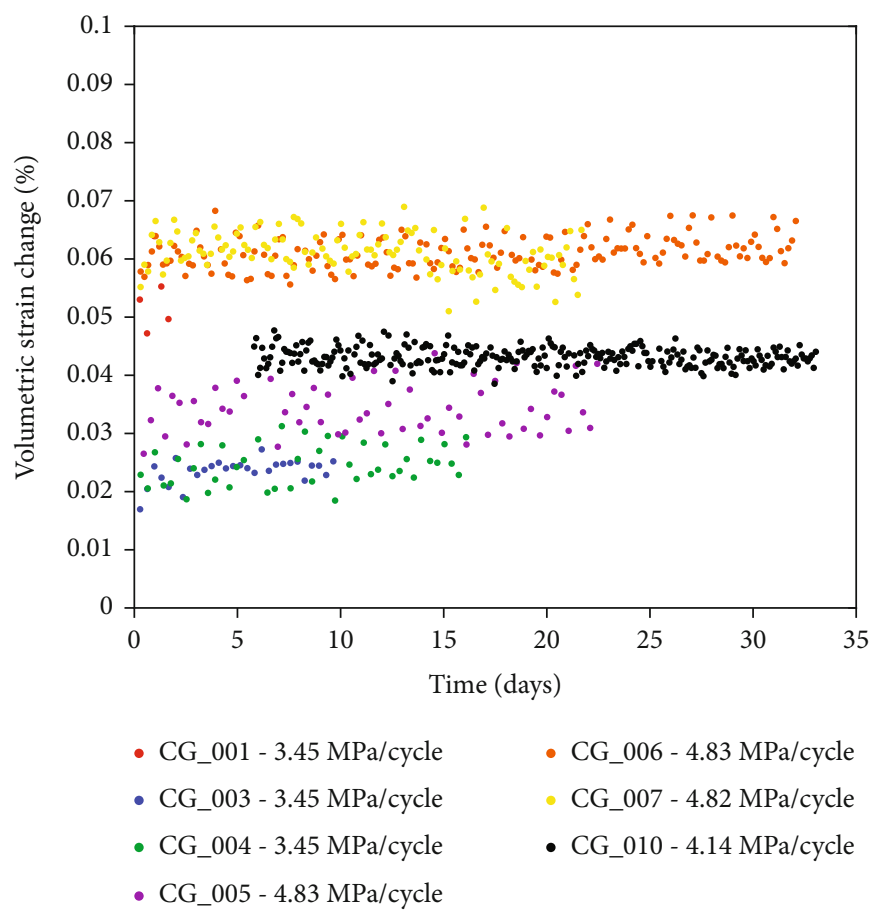

(b)

FIgURE 6: Change in volumetric strain during the unloading portion of each cycle plotted against the number of cycles (a) and time elapsed (b). Volumetric strain change is calculated from the difference in the peak and valley of each cycle during the unloading portion.

onset of grain crushing and fracturing. However, in our experiments, the mean effective stress is relatively constant during each test even as volumetric strain accumulates (Figures 5 and 6), suggesting that strain cannot be attributed solely to increasing pressure. This indicates that the corresponding changes to mechanical behavior should be attrib- uted to the stress path undertaken. Such an observation is supported by the aforementioned difference in unloading strain seen between the tests that underwent stress cycling and those that did not (i.e., CG_009).

The effect of different load setups (e.g., effective pressure, pore or confining pressure cycling, and cycle rate) can be 


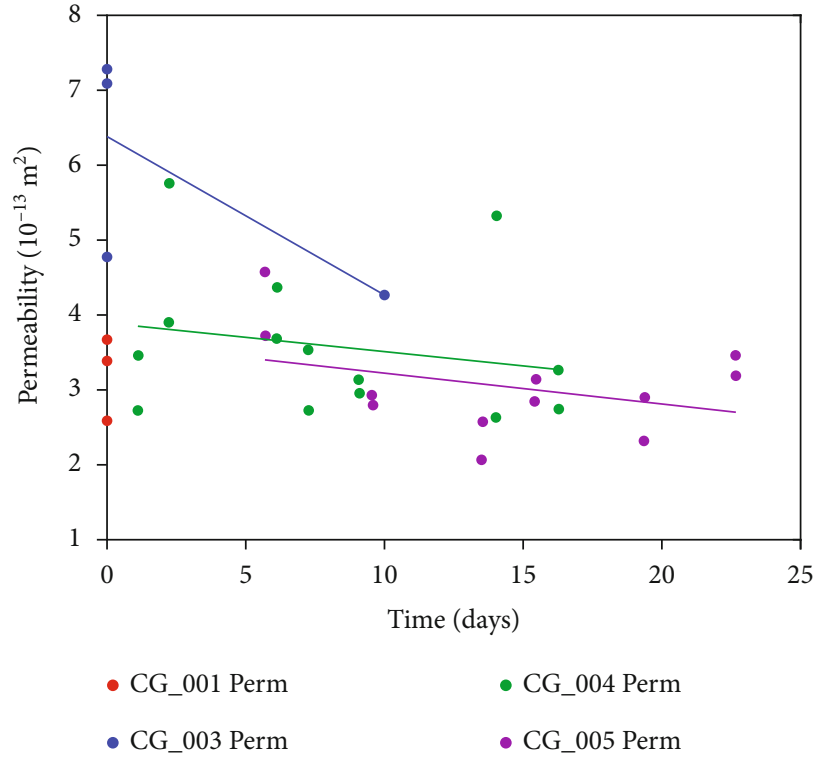

(a)

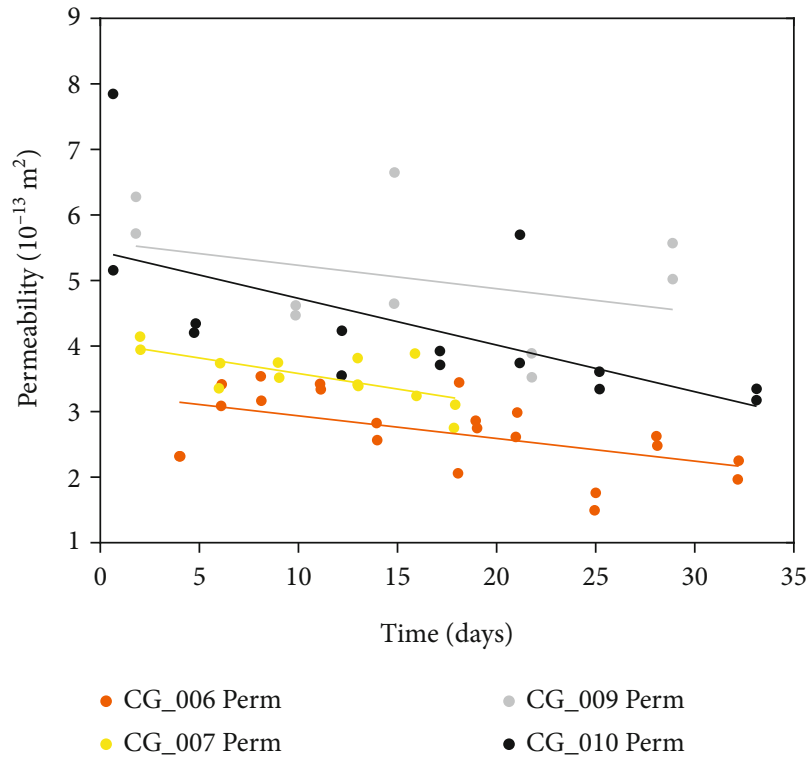

(b)

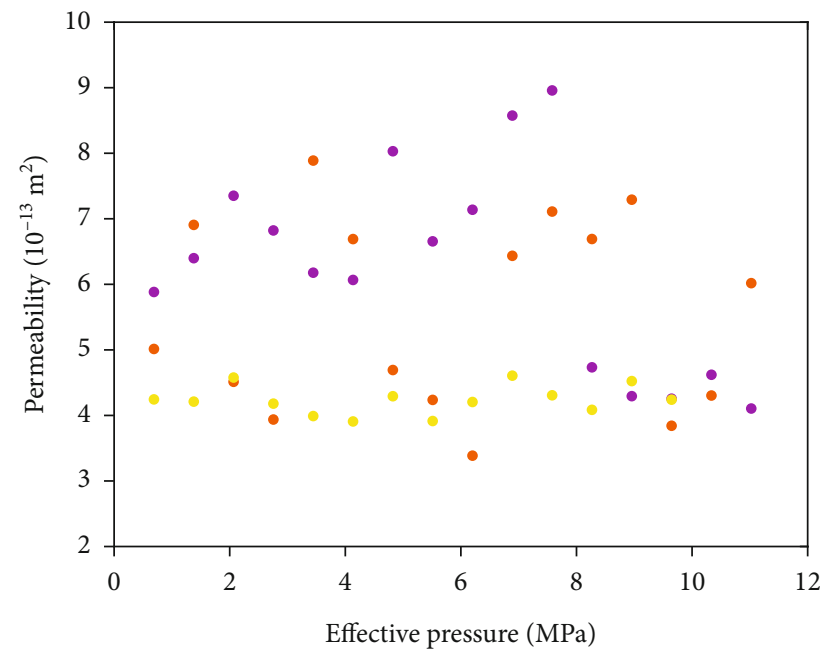

(c)

FIgure 7: Permeability determinations: (a) permeability as a function of time during 8-hour cycle tests; (b) permeability as a function of time during 4-hour cycle tests (CG_006, CG_007), 2-hour cycle tests (CG_010), and tests without stress cycling (CG_009); (c) permeability measured at intervals of $0.69 \mathrm{MPa}$ during the initial confining pressure loading of CG_005, CG_006, and CG_007, prior to stress cycling initiation.

seen in Figure 8. The volumetric strain at the peak of every five cycles was averaged to eliminate scatter and is shown in Figure 8, except for CG_001 where only five stress cycles occurred during the test. CG_010 in Figure 9(d) was corrected to remove the change in strain that occurred during the second permeability measurement (see Figure 5). For CG_009 where no cycling occurred, values were chosen from every $100^{\text {th }}$ sampling during the test (Figure $8(\mathrm{~d})$ ). All tests demonstrate that during the first 2-3 days at hydrostatic conditions, the samples experience a greater rate of strain accumulation, before becoming more linear over time. Samples deformed with faster cycle rates (Figures 8(a) and 8(b)) accumulate more volumetric strain over time than samples deformed with slower cycling rates (Figures $8(\mathrm{c})$ and $8(\mathrm{~d})$ ). However, slower cycling also leads to volumetric strain change per cycle decreasing more rapidly than faster cycling tests of CG_006 and CG_007, which continue to accumulate volumetric strain at a similar rate throughout each test. Of greater importance though is the difference in strain accumulated with fast cycling rates (CG_010) or no cycling at all (CG_009). While the 8- and 4-hour cycle tests experience relatively comparable amounts of strain over time, CG_009 and CG_010 show much less change in strain throughout the tests (Figure $8(\mathrm{~d})$ ). Although both show an initial increase in strain at the beginning of the test similar to the others, their change in strain quickly becomes linear over time. The low initial strain increase 


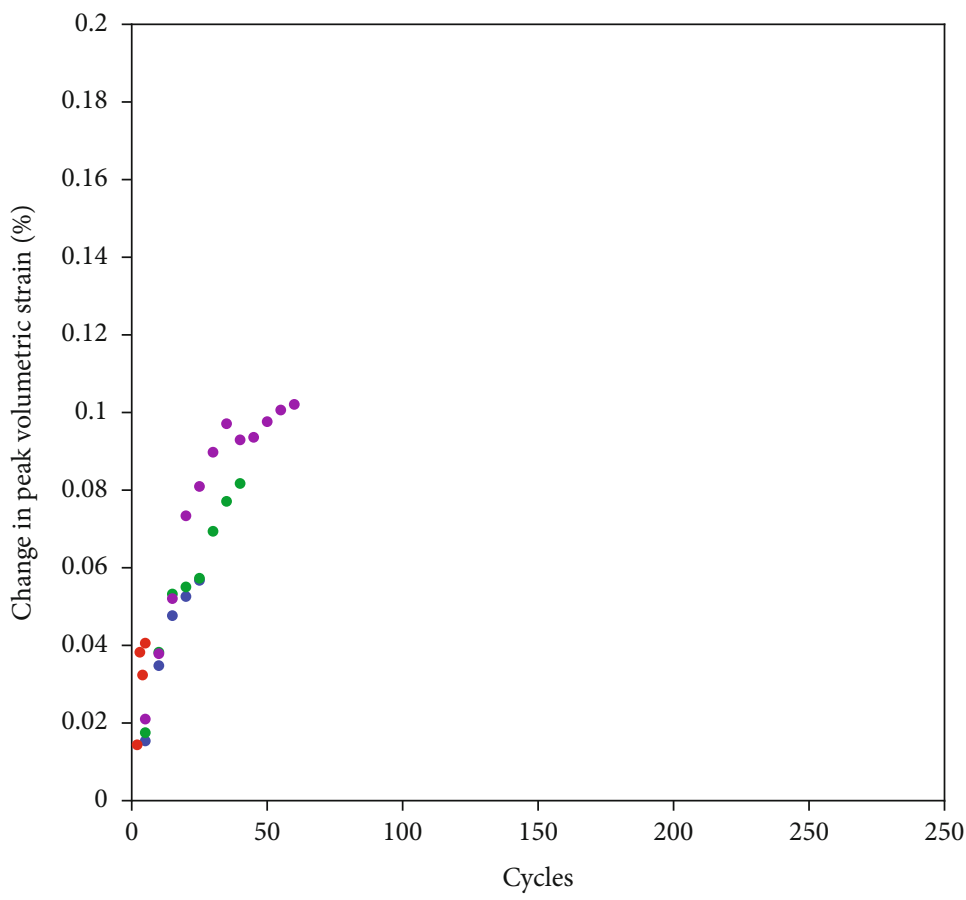

-CG_001 - 8-hour cycles -CG_004 - 8-hour cycles

-CG_003 - 8-hour cycles

-CG_005 - 8-hour cycles

(a)

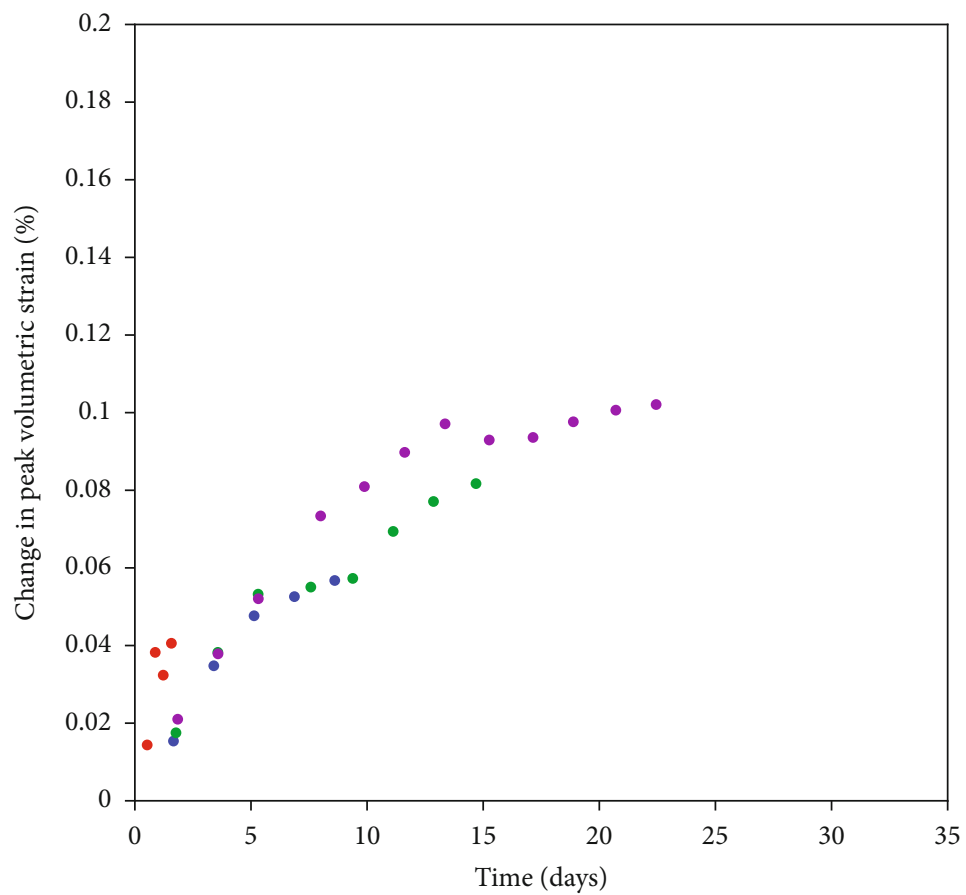

(b)

FIgUre 8: Continued. 


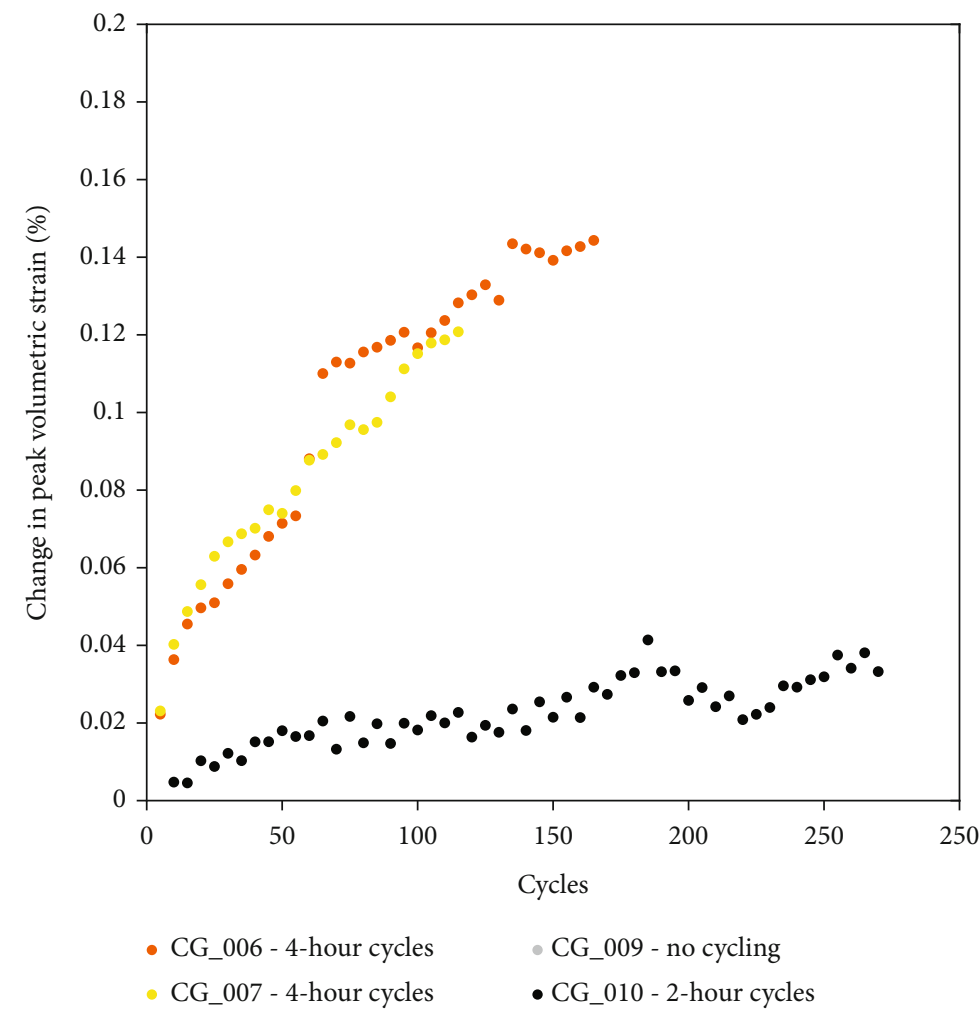

(c)

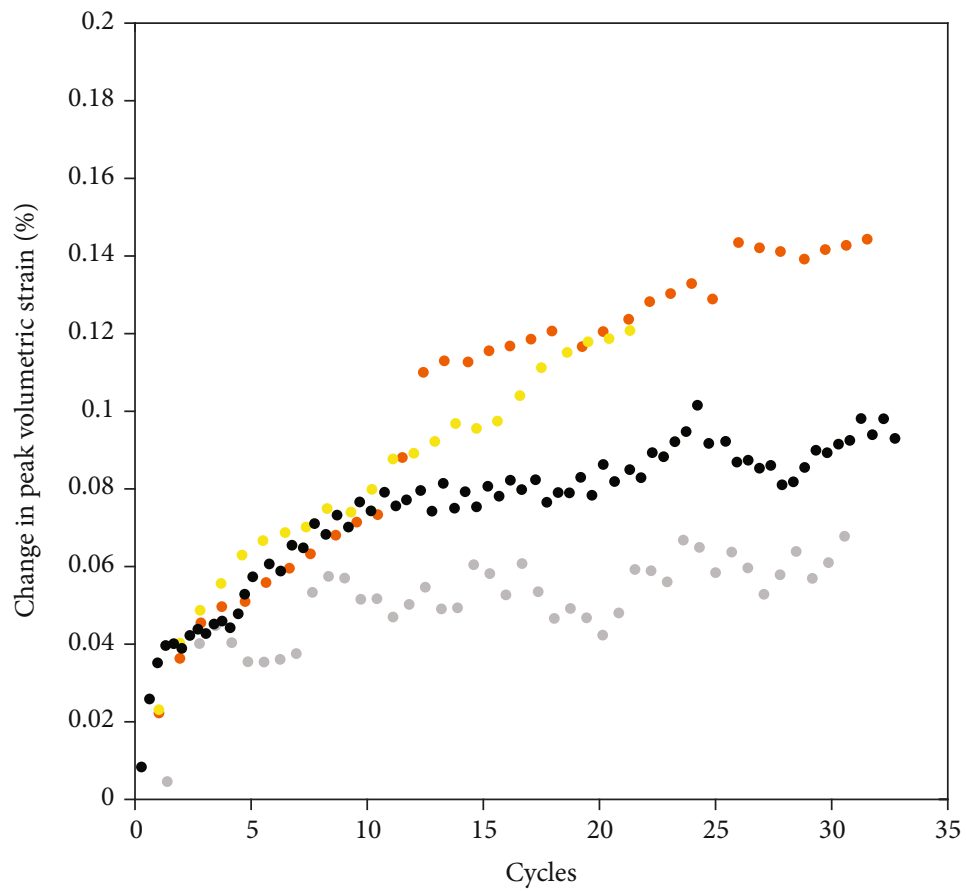

(d)

Figure 8: Average peak volumetric strain of every five cycles during the tests. Tests conducted with 8-hour cycle rates are plotted against the cycle number (a) and time elapsed (b), while samples hydrostatically loaded with 4-hour cycle rates, 2-hour cycle rates, and no stress cycling are plotted against the cycle number (c) and time elapsed (d). CG_010 in (c) only shows the strain during cycling, while CG_010 in (d) shows both the initial static period ( $\sim 5$ days) followed by the initiation of stress cycling. 


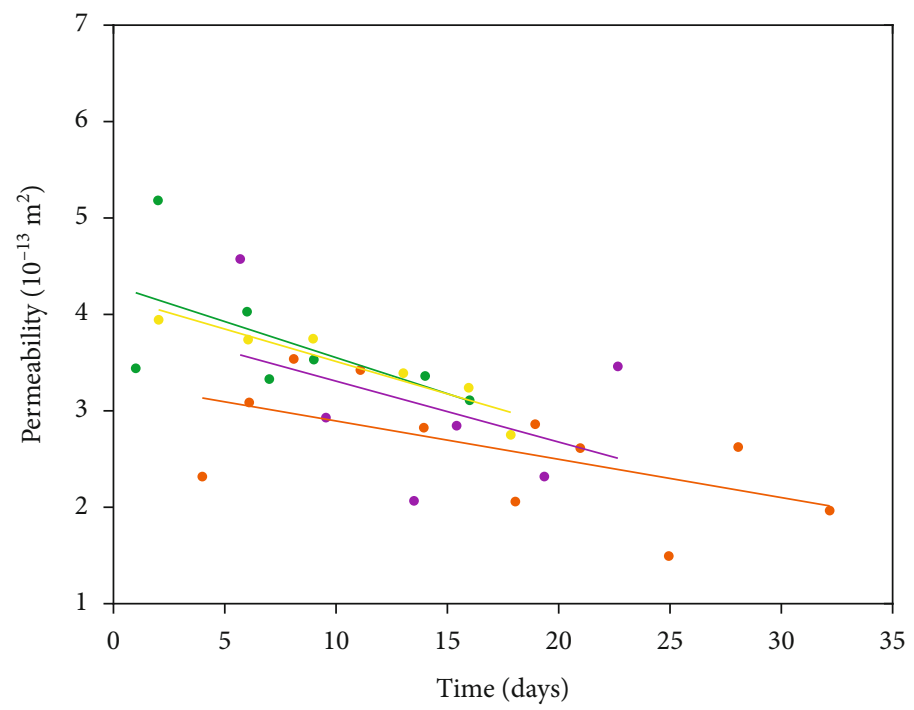

$\begin{array}{ll}\text { - CG_004- } P_{\mathrm{k}}=10.17 \mathrm{MPa} & \text { - CG_006 }-P_{\mathrm{k}}=10.76 \mathrm{MPa} \\ \text { - CG_005 }-P_{\mathrm{k}}=10.89 \mathrm{MPa} & \text {-CG_007 }-P_{\mathrm{k}}=14.48 \mathrm{MPa}\end{array}$

(a)

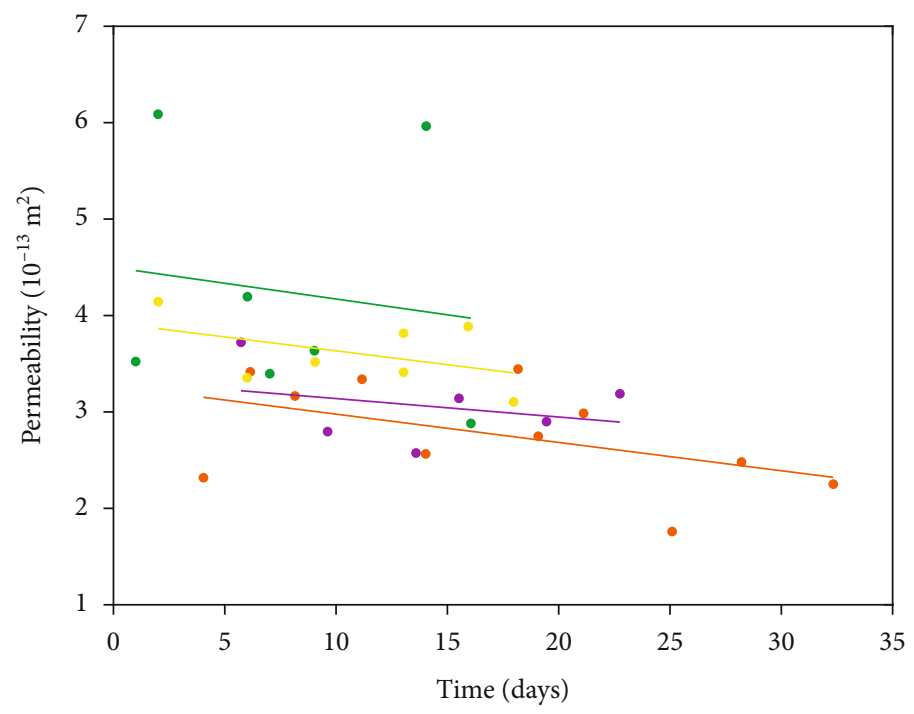

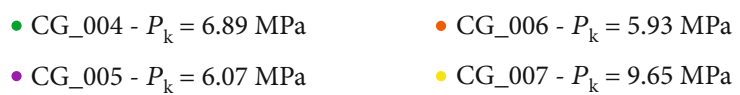

(b)

Figure 9: Continued. 


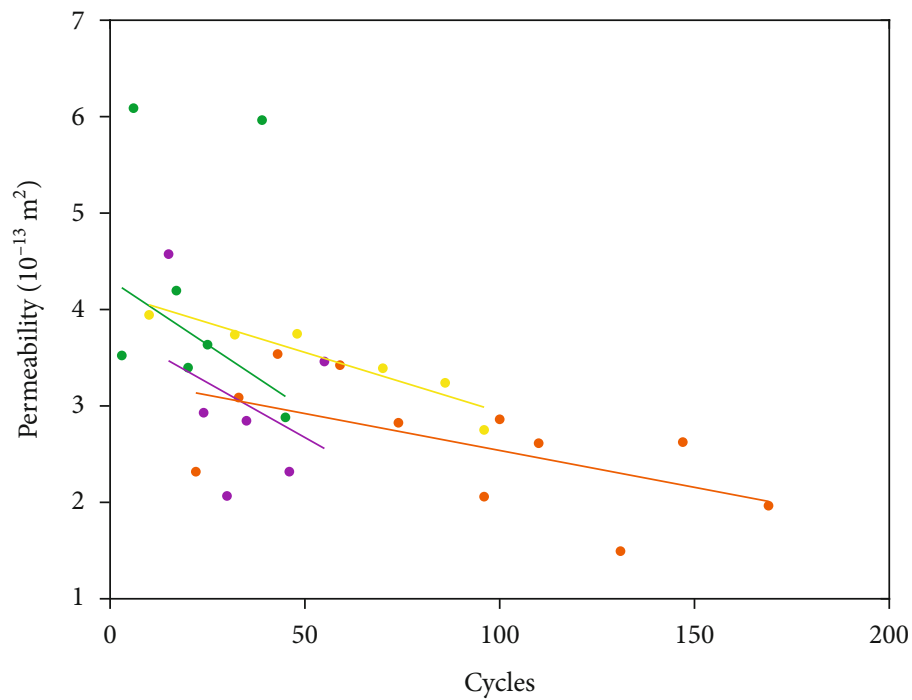

$\begin{array}{ll}\text { - CG_004 - } P_{\mathrm{k}}=10.17 \mathrm{MPa} & -\mathrm{CG}_{0} 006-P_{\mathrm{k}}=10.76 \mathrm{MPa} \\ \text { - CG_005 }-P_{\mathrm{k}}=10.89 \mathrm{MPa} & \quad \text { CG_007 }-P_{\mathrm{k}}=14.48 \mathrm{MPa}\end{array}$

(c)

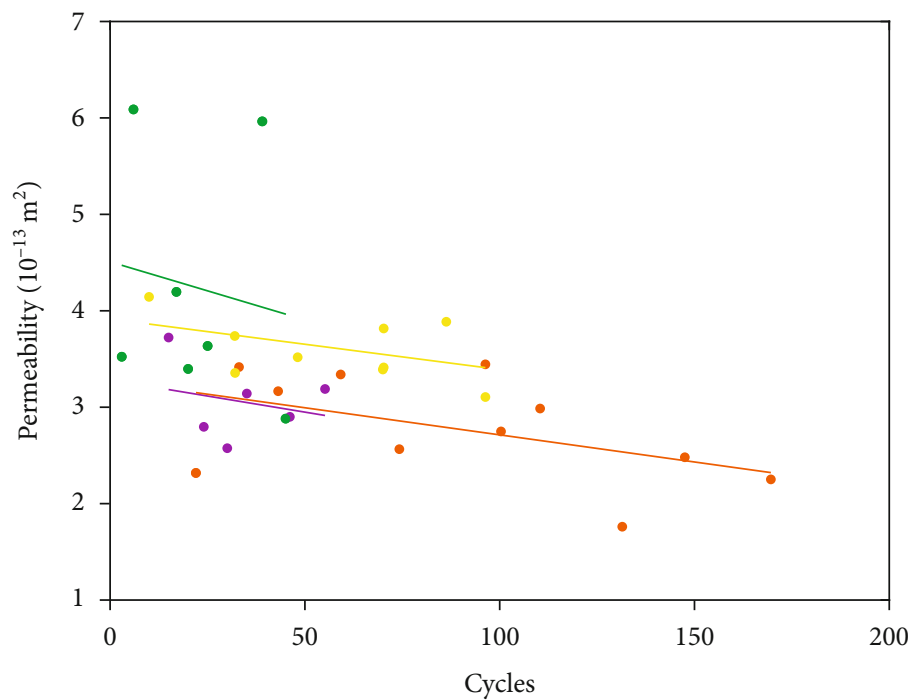

CG_004- $P_{\mathrm{k}}=6.89 \mathrm{MPa}$
CG_P $P_{\mathrm{k}}=6.07 \mathrm{MPa}$

- CG_006 - $P_{\mathrm{k}}=5.93 \mathrm{MPa}$

- CG_007 $-P_{\mathrm{k}}=9.65 \mathrm{MPa}$

(d)

Figure 9: Continued. 


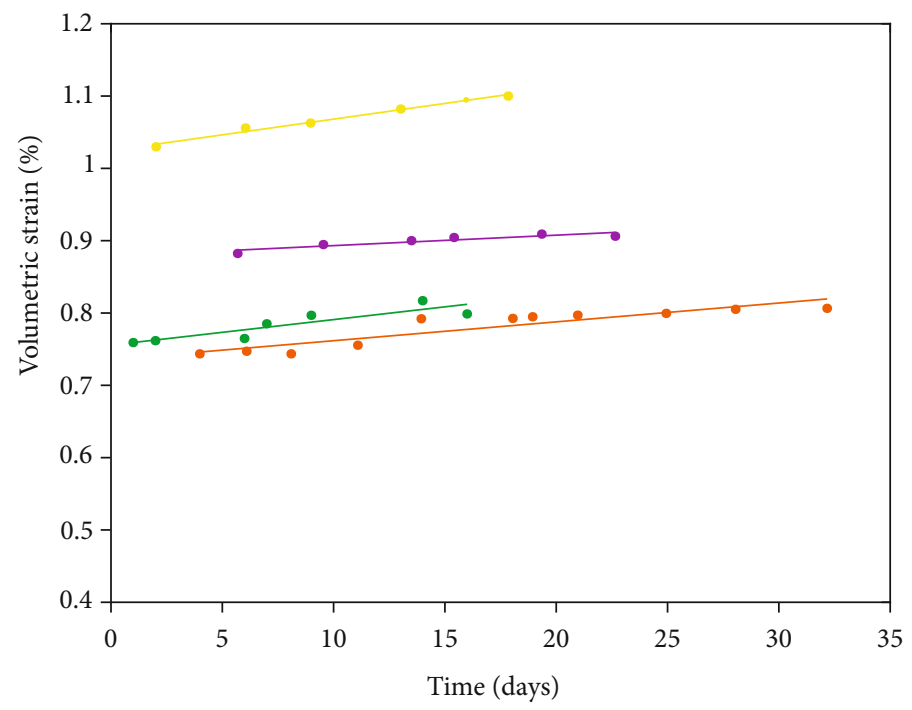

$$
\begin{array}{ll}
\text {-CG_004- } P_{\mathrm{k}}=10.17 \mathrm{MPa} & -\mathrm{CG}_{0} 006-P_{\mathrm{k}}=10.76 \mathrm{MPa} \\
\text { - CG_005 - } P_{\mathrm{k}}=10.89 \mathrm{MPa} & \text { CG_007 }-P_{\mathrm{k}}=14.48 \mathrm{MPa}
\end{array}
$$

(e)

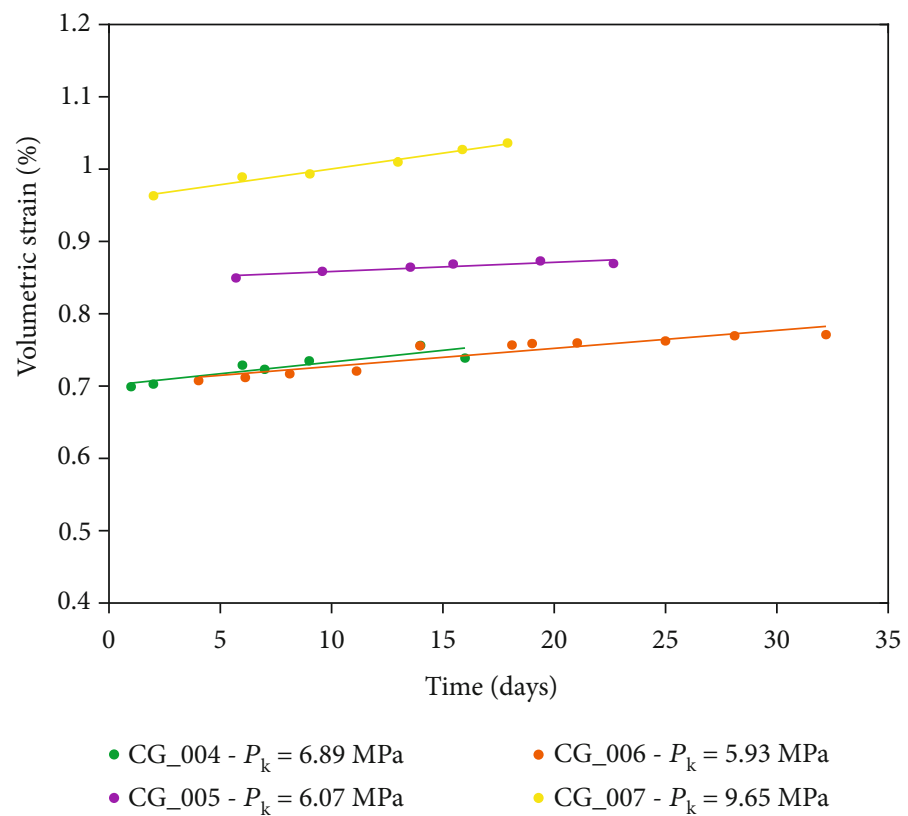

(f)

Figure 9: Comparison of permeability and volumetric strain measured during each permeability test. High $P_{\mathrm{k}}$ permeability measurements are compared with time (a) and number of cycles (c) elapsed, while low $P_{\mathrm{k}}$ permeability measurements are compared with time (b) and number of cycles (d) elapsed. Volumetric strain recorded at high $P_{\mathrm{k}}(\mathrm{e})$ and low $P_{\mathrm{k}}(\mathrm{f})$ permeability measurements is compared with time elapsed.

seen for CG_010 may be attributed to the stress cycling not beginning for the first five days of the test, so data shows the volumetric strain beginning when stress cycling was initiated.

The evolution of sample mechanical behavior can also be shown by examining the changes in elastic moduli. The bulk modulus $(B)$ represents the amount of hydrostatic stress per unit strain required to compress the bulk rock and can be expressed as:

$$
B=\frac{\Delta P_{\mathrm{eff}}}{\Delta \varepsilon_{\mathrm{v}}},
$$

where $P_{\text {eff }}$ is the effective pressure and $\varepsilon_{\mathrm{v}}$ is the volumetric strain. Using the propagation of errors method with the 
known deviations for the displacements, pressures, and sample dimensions, we determined the error for our bulk modulus measurements to be $\sim 6 \%$. However, the experimental methods used were consistent between each test, so the trends in our observations should still be consistent regardless of any error.

A greater bulk modulus generally indicates a less porous and stiffer rock volume. One can see the effect of the elastic and inelastic deformation induced during each test by comparing the bulk moduli measured during the loading and unloading of effective pressure at the start and end of each test (Table 3). The tangent of the stress-strain curves from 5 to $10 \mathrm{MPa}$ was taken as equivalent to each modulus, except for CG_005 where the tangent was only measured from 5 to $8 \mathrm{MPa}$ due to the large jump in volumetric strain above $8 \mathrm{MPa}$ (e.g., Figure 5). In all tests, regardless of duration or cycling conditions, the bulk moduli during the initial hydrostatic loading ranged from 2 to $3 \mathrm{GPa}$ (Table 3 ). Similarly, the bulk moduli during complete stress unloading (i.e., test ended and pressure reduced to $0 \mathrm{MPa}$ ) were always larger than during the initial hydrostatic loading at the start of the tests. It can also be seen that the magnitude of the unloading modulus tends to increase with test duration, with the exception of CG_007 where confining pressure was cycled instead of pore pressure. Considering the very similar test setup between CG_006 and CG_007 (cycle effective pressures, stress cycling rates), the fact that the CG_006 test was 10 days longer further lends credence to the effect of test duration when undergoing stress cycling (Table 1). Our sandstone samples were cored from the same block of Castlegate sandstone utilized in Ingraham [29] and Ingraham et al. [11]. It is noteworthy then that the bulk modulus of dry Castlegate sandstone $(11.5-13.1 \mathrm{GPa})$ is more than double any of these values [29] and is less than the water-saturated bulk modulus $(6.9 \mathrm{GPa})$ at an effective confining pressure of $22 \mathrm{MPa}$ [11].

However, the loading and unloading at the start and finish do not adequately describe how the modulus evolved throughout each test and how different stress paths lead to changes in the mechanical behavior. To this end, the bulk modulus was measured for the unloading portion of each cycle. $B$ values were compared with the number of cycles (Figure 10(a)) and number of days elapsed (Figure 10(b)). All $B$ values measured during the stress cycling exceeded the values measured at the start and end of each test (Table 3 ). The $B$ values are generally separated into two groups: the slower cycling tests (8-hour rate) and the fast cycling tests (4- and 2-hour tests). $B$ values of the slow cycling tests are on average twice that of the fast cycling tests. A further distinction can be seen in that the slow cycling tests exhibit a much greater variation from cycle to cycle. By contrast, the fast cycling tests are much less variable, particularly CG_006 and CG_007. Perhaps a more important observation is the overall trend of $B$ over the test durations. The 8-hour cycling tests all exhibit a trend of decreasing bulk moduli overall, despite their variability. The 4 -hour cycling tests initially exhibited an increase in $B$ values for the first few cycles and then remained relatively unchanged as cycles continued. $B$ values of the 2-hour cycling test CG_010 conversely exhibited an overall increase over time (Figure 10(b)).
These observations, along with the mechanical data, can clarify the effect that different loading conditions have on the evolution of mechanical behavior in sandstone.

(1) Hydrostatic cycling of confining pressure or pore pressure facilitates similar mechanical changes in our samples and provided fluid transmissibility which is sufficient to allow pore pressure maintenance. The precise confining and pore pressures maintained are of negligible importance, so long as the effective pressure is maintained

(2) xHydrostatic stress cycling at such low effective pressures induces significantly more inelastic damage overall than constant stress conditions. CG_001 was tested for only 2 days and 5 hydrostatic cycles, and its inelastic strain was more than seven times that of CG_009 even though CG_009 experienced hydrostatic creep for more than a month (Figure 4)

(3) While the total volumetric strain achieved depends on the initial sample compressibility, the loading rate and duration exert a significant degree of control on the inelastic damage induced. The peak volumetric strain increases at a diminishing rate as cycling continues (Figures $8(\mathrm{~b})$ and $8(\mathrm{~d})$ ). During the initial few days, all tests experienced consistent and relatively rapid increase in volumetric strain. 8- and 4hour cycle test volumetric strain generally increases in a nonlinear manner. Among these, the volumetric strain per day decreases more quickly for larger cycle durations and smaller cycle stress changes. With 2hour cycles, the volumetric strain increases in a logarithmic manner after cycling begins ( $\sim 4.8$ days into test). Indeed, the trend is more akin to the hydrostatic creep test of CG_009 than any of the other cycling tests (Figure $8(d)$ ). This is feasibly the result of both the higher strain rate and lower stress rate utilized for CG_010, as sandstones' mechanical behavior is known to be stress rate-dependent [30].

(4) Greater compaction occurs over time for stress cycling when the stress cycle amplitude increases. As can be seen in Figure 8, volumetric strain increases more for CG_005 over time than for the other 8-hour cycle tests. The stress cycle amplitude for CG_005 is $\sim 4.8 \mathrm{MPa}$, while for CG_001, CG_003, and CG_004, their amplitudes are closer to $\sim 3.3 \mathrm{MPa}$ (Table 2). This implies that even if mean stress during cycling is equivalent, greater stress changes during cycling will induce greater deformation over time

The most critical factor to the stress path of a sandstone would seem to be the strain or loading rate. A faster cycling rate induces less volumetric strain and thus porosity reduction. The impact of the loading rate for hydrostatic pressure may however be mitigated by reducing the magnitude of the stress change during each cycle. The implications for these observations are discussed in the following sections. 


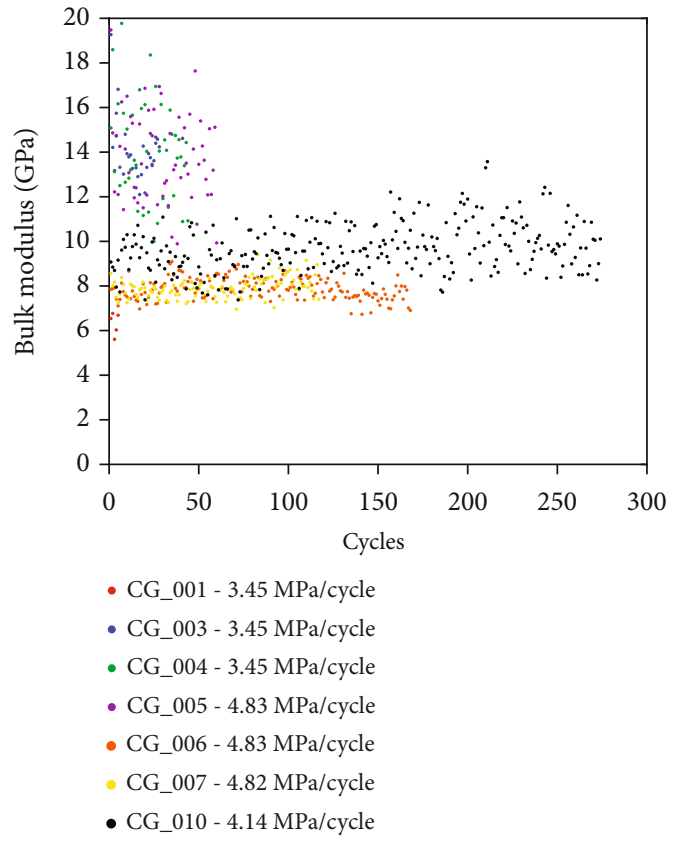

(a)

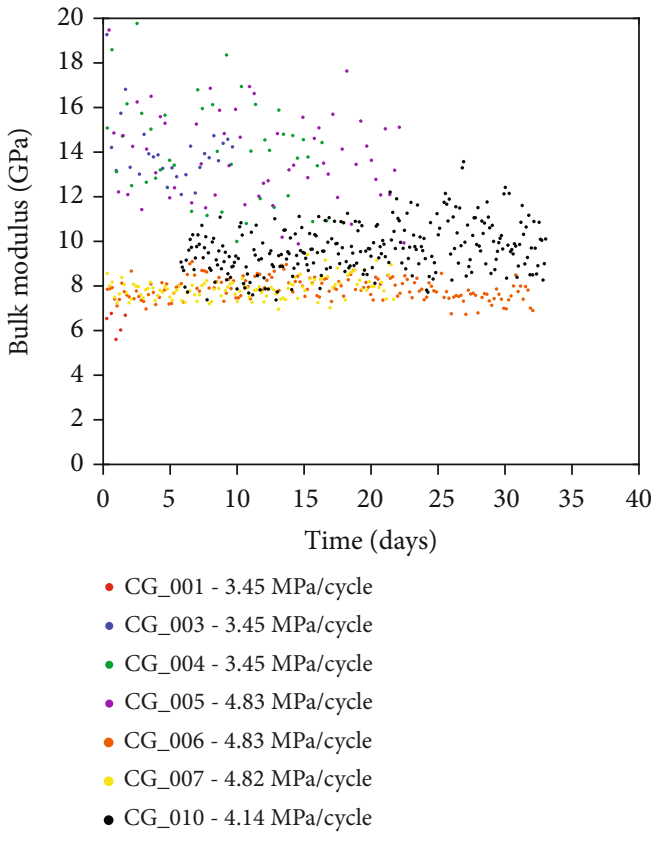

(b)

FIgURE 10: Evolution of unloading bulk moduli during hydrostatic stress cycling. Bulk modulus values are compared with the number of cycles (a) and the time elapsed (b).

4.2. Impact of the Stress Path on Sandstone Permeability. In an unfractured or intact rock, the porosity and permeability are likely to decrease with increasing hydrostatic or mean pressure [31]. Depending on the magnitude of pressure increase and degree of hysteresis in the rock, not all the original porosity and permeability will be recoverable (Table 3, Figure 7(a) for CG_003). While the relationship of permeability and porosity with pressure in porous rocks is often described by a power law or exponential function $[28,32]$, such behavior did not hold true for permeability during the initial pressurization of CG_005, CG_006, and CG_007 up to $\sim 12 \mathrm{MPa}$ (Figure $7(\mathrm{c})$ ). This pressure insensitivity during the initial loading is not unprecedented for sandstones. For example, David et al. [28] observed that permeability of Boise sandstone (porosity $=35 \%$ ) decreased quasilinearly with increasing effective stress. The initial reduction in permeability (and porosity) of sandstone is often attributed to the closing of microcracks, which tend to control permeability. But if fracture content is low and the primary porosity is intergranular pore spaces, the change in permeability will depend more on the closure of pore spaces and the nucleation of new fracture pathways at greater stresses.

In the case of our samples, the permeability evolution depends on the stress history rather than on the effective stress at any given time. Figure 9 shows how the permeability and volumetric strain evolved with different stress paths and loading conditions at effective pressures $\left(P_{\mathrm{k}}\right)$ with a similar range to the maximum and minimum pressure of each cycle (Table 2). Although there is variability from measurement to measurement, permeability decreases quasilinearly at both high and low $P_{\mathrm{k}}$ for every test. Permeability variation is generally greater at lower pressures than at higher pressures. Further, permeability decreases more rapidly per day and cycle for high pressures than for lower pressures in all tests. The volumetric strain increases similarly with continued hydrostatic cycling, though the change in volumetric strain over time is far more consistent at each pressure.

The impact of the stress path can be seen by examining the differences between the four samples shown in Figure 9. The effect of pressure on permeability is seen in CG_007, where permeability was measured at pressures $\sim 3-4 \mathrm{MPa}$ higher than the other three tests. Volumetric strain is universally higher at both pressures for CG_007, despite similarities in loading conditions to CG_006 in particular. While the permeability is not likewise lower for CG_007 than the other tests, the decrease in permeability appears far more linear per day than any of the others. This reflects the observation noted earlier that permeability will decrease more predictably at higher pressures.

The hydrostatic loading rate seems to have a greater impact on permeability than any other factor. The highest permeability values were recorded in CG_004, which was loaded with a rate of $0.8625 \mathrm{MPa} / \mathrm{hr}$ through 8 -hour cycles. CG_005 was loaded in 8-hour cycles at a rate of $1.2075 \mathrm{MPa} / \mathrm{hr}$ and displayed some of the highest permeability values with even more variation over time. The lowest permeabilities were recorded in CG_006, which was loaded in 4 -hour cycles at a rate of $2.415 \mathrm{MPa} / \mathrm{hr}$. The range of permeabilities recorded is lower for CG 006, though not so much as CG_007 which was loaded at similar rates. Although other factors may play a role, such as the maximum and minimum $P_{\text {eff }}$ during cycling, faster loading rates do seem to induce more stable decreases in permeability than not. 


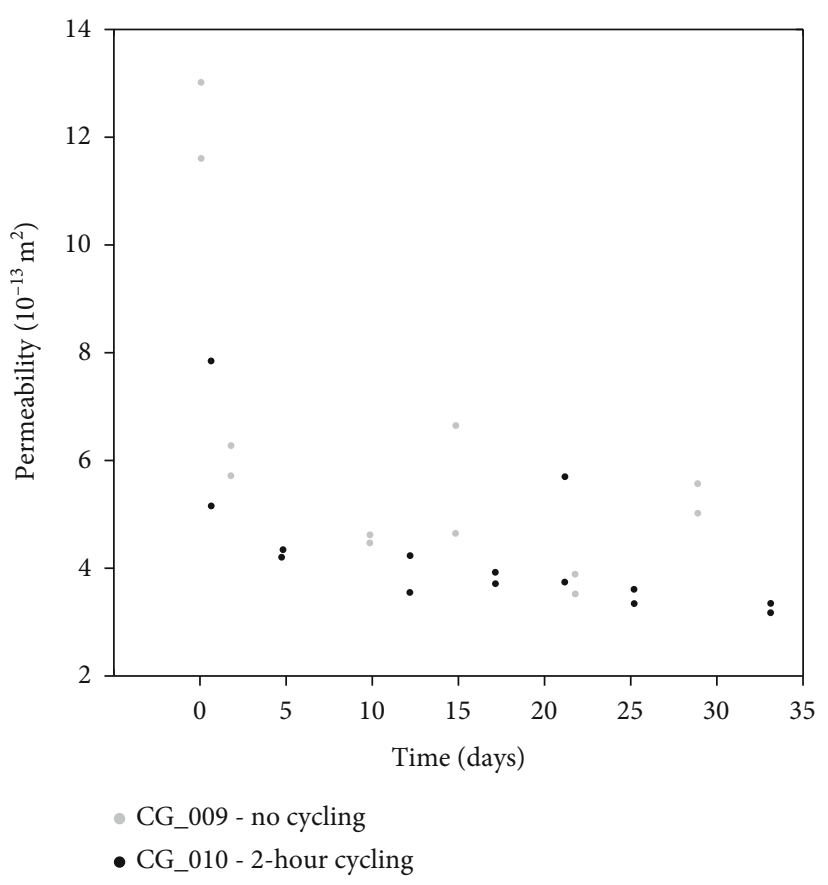

(a)

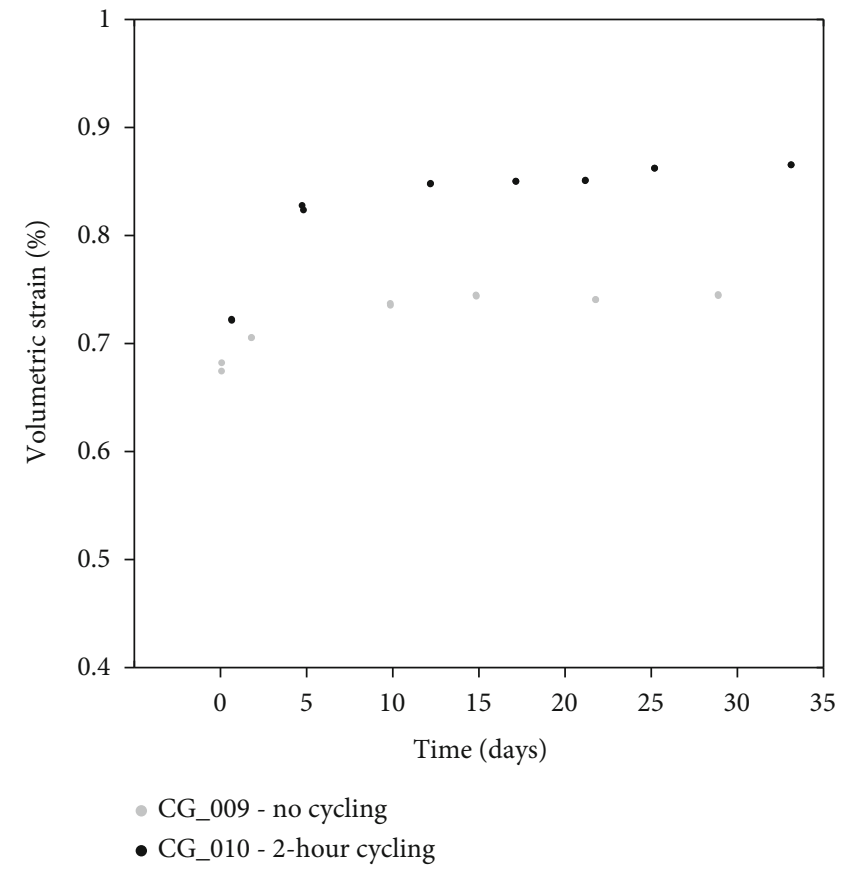

(b)

Figure 11: Permeability (a) and volumetric strain (b) measurements compared with time elapsed.

The duration of loading also seems to affect permeability measurements during hydrostatic loading. The earliest permeability measurements between cycles were conducted in CG_004. Permeability in the first $\sim 5$ days of loading deviates noticeably more than that during the later measurements from the linear trend at both high and low pressures (Figures 9(a) and 9(b)). Permeabilities were not recorded this early for the other tests, so a direct comparison is more difficult. Such an observation is similar to what is observed in Figure 11, comparing permeability and volumetric strain of CG_009 and CG_010. Permeability was measured in both CG_009 and CG_010 at the same $P_{\mathrm{k}}$, and both tests were held at a constant effective stress for the first 5 days (Figure 11(a)). During this period, permeability decayed rapidly from very high values measured on the first day, after which the change in permeability became more linear over time. A difference can be seen after 5 days though, as hydrostatic stress cycling began in CG_010. After the initial drop in permeability, CG_009 saw no consistent decrease in permeability, despite the duration of the test. By contrast, CG_010 decreases at a steady rate as stress cycling occurs, displaying less variability over time than CG_009 or any of the other stress cycling tests. A similar correlation can be seen with the volumetric strains recorded in Figure 11(b), as volumetric strain increases rapidly before only increasing incrementally over time. The difference though is clear in that volumetric strain increases more at each permeability measurement for CG_010 than for CG_009. The data shows that hydrostatic cycling of stress in CG_010 leads to greater permeability reduction and volumetric strain increase. The constant stress state of CG_009 only shows significant change in permeability and strain during the initial test duration, becoming more consistent afterwards.
From this analysis, the transport properties of an intact sandstone depend on the volumetric strain and/or the rate of change in volumetric strain. Regardless of effective stresses, permeability and volumetric strain decrease and increase, respectively, in the first few days as consolidation and grain rearrangement occur. After the initial loading period, permeability decreases more over time for samples that undergo hydrostatic cycling, which also tends to induce a greater change in volumetric strain. With faster cycling rates, permeability will be less variable over time (e.g., $\mathrm{CG}_{-}$ 007 and CG_010), just as volumetric strain will increase at a faster rate over the same testing duration.

4.3. Implications for Stress Cycling Applications. At low effective pressures, cycles in the stress state of reservoir sandstones will induce further compaction, more so than would be seen in a near static stress state. As inelastic compaction via grain rearrangement is the primary deformation mechanism at such conditions, the mechanical behavior and permeability at any given point will depend on the amount of volumetric strain change (e.g., porosity change) over time or per cycle. Perhaps more importantly, the stress path affects the variation of relevant mechanical and petrophysical properties over time, making interpreting reservoir characteristics more difficult.

Stress cycling in situ is commonly induced by both natural and anthropogenic processes. However, stress perturbations induced by fluid injection and extraction projects occur on much more rapid timescales than under natural geological conditions. Several recommendations emanating from this work can be devised to mitigate unwanted degradation of reservoir characteristics during such projects. During the initial cycling period, high porosity and permeability 
reductions should be expected at any condition. However, lower pressurization rates and stress changes during cycling should expect less reduction in porosity over time.

A tradeoff for porosity and permeability "stability" is that these conditions should also expect to see greater variability in rock mechanical and petrophysical properties than with higher loading rates and pressure changes. These depend upon the magnitude of the mean effective stress during stress cycling, since higher effective pressures diminish the impact of the unloading-loading cycles $[12,23]$. If the goal is to minimize sandstone reservoir changes during injection or recovery projects on large timescales, then ideally one would induce less than $3 \mathrm{MPa}$ of effective stress change and over the longest feasible unloading-loading period.

For a storage reservoir, this may translate to additional engineering to include a combination of additional wells, "cleaner" near-well conditions, and lower injection/withdrawal rates. Additional wells may increase costs if they do not already exist or if existing wells need to be reengineered for this purpose. Cleaner near-well conditions will perhaps allow flow rates and pressure to dissipate in a more distributed manner through the rock mass. Stimulating the near wellbore may achieve similar results. Injection/withdrawal rates are generally cost driven, and there may be a tradeoff to maintain near-wellbore permeability conditions in the context of the former.

These recommendations come with two caveats. First, if the effective stresses are sufficient to induce fracturing in the reservoir or the reservoir contains significant preexisting damage, fracture porosity may dominate sandstone petrophysical and mechanical behavior during stress cycling rather than intergranular porosity. Second, a number of authors have suggested that the amount of clay content will heavily influence any changes to sandstone porosity and permeability under both hydrostatic $[16,23]$ and triaxial stress conditions $[28,33]$. In this rock, clay content is minor; thus, its impact is expected to be small and localized. The impact of triaxial stress conditions was not studied here but is likely important in the near-wellbore environment. Understanding the impact of stress cycling and stress history on a sandstone reservoir requires sufficient characterization of the reservoir rocks [34].

\section{Conclusions}

Hydrostatic stress cycling tests were conducted over the course of weeks with eight samples of Castlegate sandstone. The impact of different stress paths on the mechanical and petrophysical behavior of the sandstones was analyzed by varying the loading rate, magnitude of stress change, pressure conditions, and duration of the tests. Permeability was determined at numerous intervals and pressures to quantify how permeability evolves during stress cycling. Tests showed that mechanical compaction increased nonlinearly with increasing hydrostatic stress cycles and that different stress paths altered the mechanical properties of sandstone without requiring significant permanent damage. Permeability evolution was shown to be dependent upon the volumetric strain change over time. Slower cycle loading rates or constant effective stresses were shown to experience less reduction and more variability in permeability determined after the first few days of testing. Observations were used to derive recommendations for induced stress cycling in situ for sandstone reservoirs. Additional work with hydrostatic cycling of sandstones of different porosity and damage content may yield further insight into the how wells evolve during injection and extraction applications.

\section{Data Availability}

The mechanical test and permeability test data reported in this study are available from the second author (sjbauer@sandia.gov) upon request.

\section{Conflicts of Interest}

The authors declare that there are no conflicts of interest regarding the publication of this paper.

\section{Acknowledgments}

The authors would like to thank Greg Flint for sample preparation and conducting the experiments. The authors would also like to thank Charles Choens for reviewing and offering commentary on the manuscript. Sandia National Laboratories is a multimission laboratory managed and operated by the National Technology and Engineering Solutions of Sandia, LLC., a wholly owned subsidiary of Honeywell International, Inc., for the U.S. Department of Energy's National Nuclear Security Administration under contract DE-NA0003525 (SAND2021-4039 J).

\section{References}

[1] R. H. Sibson, "Crustal stress, faulting and fluid flow," Geological Society, London, Special Publications, vol. 78, no. 1, pp. 6984, 1994.

[2] R. S. Stein, "The role of stress transfer in earthquake occurrence," Nature, vol. 402, no. 6762, pp. 605-609, 1999.

[3] J. M. Davison, I. Foo, F. Ellis, and A. Proughten, “The in-situ stress response of reservoirs to pressure reduction followed by pressure increase: depletion and rebound stress paths from two case studies," in 50th U.S. Rock Mechanics/Geomechanics Symposium, Houston, Texas, 2016.

[4] M. B. Dusseault, "Deep injection disposal: environmental and petroleum geomechanics," in ISRM International Symposium 6th Asian Rock Mechanics Symposium, New Delhi, India, 2010.

[5] K. Heffer, "Geomechanical influences in water injection projects: an overview," Oil \& Gas Science and Technology, vol. 57, no. 5, pp. 415-422, 2002.

[6] P. Martínez-Garzón, G. Kwiatek, M. Bohnhoff, and G. Dresen, "Volumetric components in the earthquake source related to fluid injection and stress state," Geophysical Research Letters, vol. 44, no. 2, pp. 800-809, 2017.

[7] Z. Ye, M. Janis, and A. Ghassemi, "Injection-driven shear slip and the coupled permeability evolution of granite fractures for EGS stimulation," in 51st U.S. Rock Mechanics/Geomechanics Symposium, San Francisco, California, USA, 2017. 
[8] J. Rutqvist, "Analysis of injection-induced micro-earthquakes in a geothermal steam reservoir," in The 42nd U.S. Rock Mechanics Symposium (USRMS), San Francisco, California, 2008.

[9] J. S. Yoon, A. Zang, and O. Stephansson, "Numerical investigation on optimized stimulation of intact and naturally fractured deep geothermal reservoirs using hydro-mechanical coupled discrete particles joints model," Geothermics, vol. 52, pp. 165-184, 2014.

[10] Y. Bernabe, "The effective pressure law for permeability during pore pressure and confining pressure cycling of several crystalline rocks," Journal of Geophysical Research: Solid Earth, vol. 92, no. B1, pp. 649-657, 1987.

[11] M. D. Ingraham, S. J. Bauer, K. A. Issen, and T. A. Dewers, "Evolution of permeability and Biot coefficient at high mean stresses in high porosity sandstone," International Journal of Rock Mechanics and Mining Sciences, vol. 96, pp. 1-10, 2017.

[12] E. Shalev, V. Lyakhovsky, A. Ougier-Simonin, Y. Hamiel, and W. Zhu, "Inelastic compaction, dilation and hysteresis of sandstones under hydrostatic conditions," Geophysical Journal International, vol. 197, no. 2, pp. 920-925, 2014.

[13] R. M. Holt, E. Fjær, A. M. Raaen, and C. Ringstad, "Influence of stress state and stress history on acoustic wave propagation in sedimentary rocks," in Shear Waves in Marine Sediments, J. M. Hovem, M. D. Richardson, and R. D. Stoll, Eds., pp. 167174, Springer, Dordrecht, 1991.

[14] X. Ma and M. D. Zoback, "Static and dynamic response of Bakken cores to cyclic hydrostatic loading," Rock Mechanics and Rock Engineering, vol. 51, no. 6, pp. 1943-1953, 2018.

[15] D. Zivar, J. Foroozesh, P. Pourafshary, and S. Salmanpour, "Stress dependency of permeability, porosity and flow channels in anhydrite and carbonate rocks," Journal of Natural Gas Science and Engineering, vol. 70, p. 102949, 2019.

[16] N. R. Warpinski and L. W. Teufel, "Determination of the effective-stress law for permeability and deformation in lowpermeability rocks," SPE Formation Evaluation, vol. 7, no. 2, pp. 123-131, 1992.

[17] F. Ma, S. He, H. Zhu, Q. Xie, and C. Jiao, "The effect of stress and pore pressure on formation permeability of ultra-lowpermeability reservoir," Petroleum Science and Technology, vol. 30, no. 12, pp. 1221-1231, 2012.

[18] N. B. Nagel, "Compaction and subsidence issues within the petroleum industry: from Wilmington to Ekofisk and beyond," Physics and Chemistry of the Earth, Part A: Solid Earth and Geodesy, vol. 26, no. 1-2, pp. 3-14, 2001.

[19] A. Zang, G. Zimmermann, H. Hofmann, O. Stephansson, K. B. Min, and K. Y. Kim, "How to reduce fluid-injection-induced seismicity," Rock Mechanics and Rock Engineering, vol. 52, no. 2, pp. 475-493, 2019.

[20] P. Baud, P. Meredith, and E. Townend, "Permeability evolution during triaxial compaction of an anisotropic porous sandstone," Journal of Geophysical Research: Solid Earth, vol. 117, no. B5, 2012.

[21] T. F. Wong and P. Baud, "Mechanical compaction of porous sandstone," Oil \& Gas Science and Technology, vol. 54, no. 6, pp. 715-727, 1999.

[22] J. Zhang, T. F. Wong, and D. M. Davis, "Micromechanics of pressure-induced grain crushing in porous rocks," Journal of Geophysical Research: Solid Earth, vol. 95, no. B1, pp. 341352, 1990.
[23] T. N. Dey, "Permeability and electrical conductivity changes due to hydrostatic stress cycling of Berea and Muddy J sandstone," Journal of Geophysical Research: Solid Earth, vol. 91, no. B1, pp. 763-766, 1986.

[24] G. M. Keaney, P. Meredith, S. Murrell, and J. Barker, "Determination of the effective stress laws for permeability and specific storage in a low porosity sandstone," in Gulf Rocks 2004, the 6th North America Rock Mechanics Symposium (NARMS), Houston, Texas, 2004.

[25] M. J. Heap, P. Baud, P. G. Meredith, A. F. Bell, and I. G. Main, "Time-dependent brittle creep in Darley Dale sandstone," Journal of Geophysical Research: Solid Earth, vol. 114, no. B7, 2009.

[26] A. A. DiGiovanni, J. T. Fredrich, D. J. Holcomb, and W. A. Olsson, "Microscale damage evolution in compacting sandstone," Geological Society, London, Special Publications, vol. 289, no. 1, pp. 89-103, 2007.

[27] C. L. Zhang, G. Armand, N. Conil, and B. Laurich, "Investigation on anisotropy of mechanical properties of CallovoOxfordian claystone," Engineering Geology, vol. 251, pp. 128$145,2019$.

[28] C. David, T. F. Wong, W. Zhu, and J. Zhang, "Laboratory measurement of compaction-induced permeability change in porous rocks: implications for the generation and maintenance of pore pressure excess in the crust," Pure and Applied Geophysics, vol. 143, no. 1-3, pp. 425-456, 1994.

[29] M. D. Ingraham, Investigation of localization and failure behavior of Castlegate sandstone using true triaxial testing, [Ph.D. thesis], Clarkson University, ProQuest Dissertations Publishing, 2012.

[30] J. Hadizadeh and R. D. Law, "Water-weakening of sandstone and quartzite deformed at various stress and strain rates," International Journal of Rock Mechanics and Mining Sciences \& Geomechanics Abstracts, vol. 28, no. 5, pp. 431-439, 1991.

[31] M. E. French, F. M. Chester, J. S. Chester, and J. E. Wilson, "Stress-dependent transport properties of fractured arkosic sandstone," Geofluids, vol. 16, no. 3, 551 pages, 2016.

[32] J. R. Rice, "Chapter 20 fault stress states, pore pressure distributions, and the weakness of the San Andreas fault," in International Geophysics, vol. 51, pp. 475-503, Academic Press, 1992.

[33] X. Liu, M. Xu, and K. Wang, "Mechanism of permeability evolution for reservoir sandstone with different physical properties," Geofluids, vol. 2018, 16 pages, 2018.

[34] A. Torabi, H. Fossen, and A. Braathen, "Insight into petrophysical properties of deformed sandstone reservoirs," AAPG Bulletin, vol. 97, no. 4, pp. 619-637, 2013. 